\title{
Data-Based RC Dynamic Modelling to Assessing the In-Situ Thermal Performance of Buildings. Analysis of Several Key Aspects in a Simplified Reference Case toward the Application at On-Board Monitoring Level
}

\author{
Yessenia Olazo-Gómez ${ }^{1}$, Héctor Herrada ${ }^{2}{ }^{\oplus}$, Sergio Castaño ${ }^{2}{ }^{\circledR}$, Jesús Arce ${ }^{1}$, Jesús P. Xamán ${ }^{1}$ \\ and María José Jiménez ${ }^{2, *(1)}$ \\ 1 Tecnológico Nacional de México/CENIDET, Cuernavaca, Morelos CP 62490, Mexico; \\ olazo@cenidet.edu.mx (Y.O.-G.); jesus.al@cenidet.tecnm.mx (J.A.); jesus.xv@cenidet.tecnm.mx (J.P.X.) \\ 2 Energy Efficiency in Buildings R\&D Unit, CIEMAT, 28040 Madrid, Spain; hector.herrada@psa.es (H.H.); \\ sergio.castano@psa.es (S.C.) \\ * Correspondence: mjose.jimenez@psa.es; Tel.: +34-950-38-7900
}

Received: 30 July 2020; Accepted: 10 September 2020; Published: 14 September 2020

\begin{abstract}
This paper reports the application of RC dynamic models for assessing thermal performance of buildings from in-situ tests (obtaining the $U$ value for the walls, and the UA value and $g A$ value for the whole buildings). The following aspects which are relevant to this approach have been systematically analyzed: The effect of the solar radiation on the heat flux through the opaque walls versus the performance of the models including this effect, the optimum number of nodes required to represent the thermal systems, the assignment of inputs and outputs and the length of the test period. Additionally, several options modelling relevant effects using unmeasured variables were studied to evaluate the feasibility to reduce the cost and intrusiveness of the measurement devices required to obtain accurate results. Data series recorded under different experimental conditions were considered to analyze the robustness and validity of the results. The performance of the models for each of these different test conditions is discussed. The uncertainties estimated using the described method for the $\mathrm{U}$ values of the opaque walls, and the UA and gA values of the whole building, are, respectively, $2.8 \%, 4.2 \%$ and $2.3 \%$. The feasibility to model relevant effects using unmeasured variables has been demonstrated. A simplified and well-known building has been used as a case study, reinforcing and complementing the validation criteria.
\end{abstract}

Keywords: building energy performance; building envelope; outdoor testing; in-situ tests; thermal parameters; performance indicators; dynamic analysis

\section{Introduction}

The increasing consciousness on energy and environmental issues is leading to an intensification of research that can contribute to guide the elaboration of regulations, aiming to save building energy use and emissions of pollutants, frequently based on theoretical calculations. However, the theoretical and actual building energy performance can show significant differences. This problem has been evidenced and discussed by some researchers [1,2], showing that more scientific work is necessary to enhance the reliability of the building energy simulation design tools and the procedures for assessing the as-built energy performance. This research is also required to produce scientific background to support the elaboration of regulations and standards for energy savings in buildings [3]. The Strategic Plan [4] of the Energy in Buildings and Communities (EBC) Technology Collaboration Programme (TCP) of the International Energy Agency (IEA), considers among its research themes the need for 
tools that identify sources of performance gaps and provide feedback to designers, building owners and operators. It also observes the role of experimental research in understanding the sources of performance gaps in the operational phase and states its usefulness to evaluate opportunities for refurbishment and post-refurbishment performance.

Some published studies considered the effect on the performance gap of the differences between the climate data files used for the simulations and the actual weather [5]. Some authors focus their analysis on the effect of climate change [6]. These works identified relevant deviations on the building energy performance due to the differences between the traditionally used climate data files and the updated meteorological data. The gap related to the climate change has a relevant impact in several areas. Some authors discus its effect on the conservation framework for wisely protecting heritage resources in a changing climate [7]. Some studies identify the difference between the standard and actual occupancy patterns as a relevant contribution to this performance gap [5,8]. Several studies apply sensitivity analysis to identify the effects which are more relevant on the performance gap when they are different from those assumed for simulations. The reference [9] reports the analysis of the deviation from design specifications that could be introduced by poor workmanship on the construction process. It identified that the execution of the building envelope is very relevant regarding the overall building energy performance, particularly the thickness of the insulation layers and the airtightness. The work reported in [10] evaluated the effect of the different hypotheses used for the thermal performance assessment based on simulation of two office buildings. This work concluded that the deviation due to the hypothesis used for the simulation and the actual measured values can triplicate the energy demands. The biggest influence identified is due to the slab-on-grade modelling. The infiltration rate has been also identified as a relevant contribution to this performance gap. The reference [11], also reports a work based on sensitivity analysis quantifying the differences on the building energy performance introduced by different values of the parameters that characterize the building envelope. This work proposes a methodology based on this analysis to identify the most appropriate retrofit measures of existing buildings.

The building envelope is a very influencing element on the energy performance of the buildings. This issue is corroborated by several projects in this context which are considering the aforementioned identified performance gap [12,13]. Experimental assessment procedures can contribute to solve the problems caused by this performance gap [14]. Different data-based dynamic modelling approaches can be applied to assess the in-situ thermal performance of the building envelope. These approaches are different regarding complexity and also in terms of reliability [15]. These methods can be steady-state or averaging methods that can be seen as integral approaches or dynamic approaches that can be seen as differential approaches. Some simplified methods based on averages that were developed and fully applied in the past are still being used [16]. Nevertheless, the applicability of these methods has certain limitations regarding the test conditions or regarding the length of the test campaign. Such limitations make difficult, and sometimes impossible, its applicability to buildings and/or, mainly buildings in locations under warm weather and high levels of solar radiation.

Coheating tests are used to obtain the heat-loss coefficient of full-sized empty buildings from in-situ measurements conducted in the heating season for a period of at least two weeks $[17,18]$. This parameter is obtained from steady-state calculations based on linear regression from daily averages. This method has been developed, assessed and largely used in locations with cold weather and relatively low levels of solar radiation. However, actual thermal performance of the building envelope and its accurate characterization are also important in emplacements where the weather is sunny and warm and hot [19-23]. The quick U-building (QUB) method is a relatively new method used to measure the overall heat loss coefficient of empty buildings during one to two nights by applying heating power and by measuring the indoor and the outdoor temperatures [24]. This reference demonstrates that the accuracy of the QUB method depends on several aspects, such as the boundary conditions (solar radiation), initial conditions (initial power and temperature distribution in the walls) and on the design of QUB experiment (heating power and duration). Development and validation 
of reliable procedures, with generalized applicability to in-use buildings and including a sunny and warm climate and capable of dealing with the dynamic features of these generalized conditions, are also necessary to achieve the readiness required for deployment in this context. Uncertain accuracy, high cost and intrusiveness limit the implementation of some experimental methods. Additionally, the increasing availability of smart technologies and on-board monitoring systems offers a huge amount of data that could be used for the assessment of building energy performance of in-use buildings. The development and validation of reliable procedures together with the access to smart technologies and on-board monitoring systems could facilitate the introduction of performance assessment procedures in normative and commercial applications.

Dynamic issues are relevant to the energy performance of walls and whole buildings $[25,26]$. Dynamic data-based modelling techniques are promising to carry out the energy performance assessment of in-use buildings overcoming some problems that arise when some average and linear regression methods are applied. Wide activity has been developed in this area [3,27], with a broad development on techniques for the identification of the parameters characterizing the thermal performance of building components, from dynamic tests in outdoor test cells, usually obtained from linear and time-invariant models [28]. The extension and generalization of the current scope of application of these techniques is not simple, but some researches are undertaking this challenge [29].

This article deals with the application of RC dynamic models for assessing the in-situ thermal performance of walls (identifying the $U$ value) and whole buildings (identifying the UA value and gA value). These models use an electrical analogy representing the thermal system to obtain the required parameters. LORD software has been used as tool to identify the required parameters from the measured data series [30]. The potential to apply this approach to in-use buildings has been demonstrated by a previously published work [29]. This paper repots a further systematic analysis focusing on the following aspects: the effect of the solar radiation on the heat flux through the opaque walls versus the performance of the models including this effect. Although previous work [31] analyzed this issue applying another method and concluded that neglecting this effect is convenient, a deeper analysis is here reported. This work also studied the optimum number of nodes required to represent the thermal systems, the assignment of inputs and outputs and the length of the test period. Additionally, several options modelling relevant effects using unmeasured variables were studied to evaluate the feasibility to reduce the cost and intrusiveness of the measurement devices required to obtain accurate results. The feasibility to model relevant effects using unmeasured variables has been demonstrated.

A building which is well-known and simplified has been considered for this study. Data series recorded under very different experimental conditions were used to analyze the robustness and validity of the results. The performance of the models for each of these different test conditions is discussed. The detailed information of the construction of the building which is available, including accurate geometrical parameters and thermal properties of its construction materials, strengthens and complements the criteria for validation. This issue together with the simplicity of the building, the oversizing of its test set up and length, and the richness of the weather conditions throughout the test campaign, are relevant features to make this case study suitable to corroborate, complement, and extend some findings from previous works [31]. These analyses and comparisons give background to support the criteria for selecting the best model among the considered candidates and the minimum set of variables required to guarantee an adequate accuracy of the analysis. The objective is to find the simplest and cheapest models giving enough accuracy. These requisites are crucial regarding deployment in commercial applications.

The same benchmark data have been used as support to other research focusing on different aspects and methodologies. Rouchier et al. [32] report the application of Sequential Monte Carlo (SMC) for the on-line estimation of the heat loss coefficient (HLC) of a building. Chávez et al. [31] analyzed systematically different key aspects of a dynamic integrated method applied to assessing the in-situ thermal performance of walls and whole buildings and demonstrated the reliability of that method. 
The analysis reported in this paper added to other published works [31] constitutes a collection of methods systematically applied and validated by means of their application to the same test set up and high quality benchmark data. This material contributes as a strong basis and background to the development of procedures for the in-situ performance assessment of the building fabric, using data recorded by on-board monitoring systems, from test campaigns conducted under a large variety of weather and test conditions.

The next sections are organized as follows: Section 2 briefly describes the simplified building, the boundary conditions and test set up used as a case study in this research work; Section 2 also introduces the methodology that has been applied as well as the steps followed for the analysis, first of the opaque walls and afterwards of the whole building; Section 3 reports and discusses the results; and, finally, Section 4 synthesizes the main findings of the work.

\section{Materials and Methods}

\subsection{Benchmark Set up and Data}

A test box performing as a simplified building was used in this research work. It was built within the framework of IEA EBC Annex 58. The same building was used as benchmark and support for previous research works in this context. This building and the experiment set up are briefly presented hereafter. Further information is reported in reference [15].

\subsubsection{The Building (Test Box)}

The simplified building is a test box that consists of a cubic structure (Figure 1). Its exterior dimensions are $120 \times 120 \times 120 \mathrm{~cm}^{3}$, and the ceiling, floor and walls are all $12 \mathrm{~cm}$ thick. The south wall has a wooden-framed window $71 \times 71 \mathrm{~cm}^{2}$ and a glazed area of $52 \times 52 \mathrm{~cm}^{2}$. It is suspended over a structure that avoids contact with the ground. Due to its airtight construction, air leakage can be assumed as negligible.

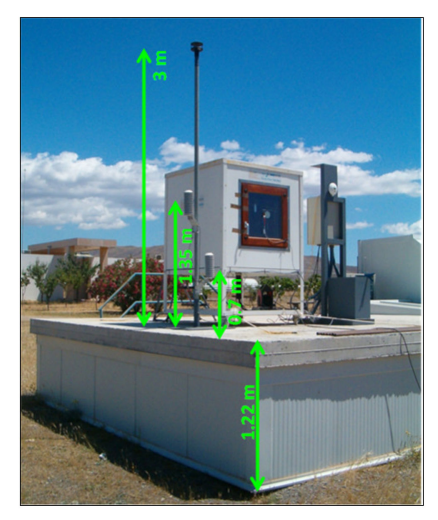

(a)

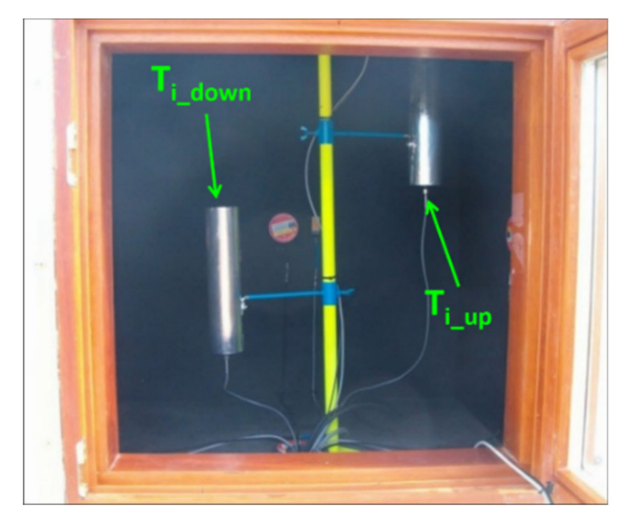

(b)

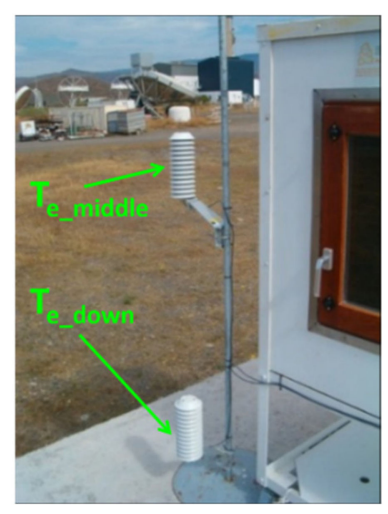

(c)

Figure 1. Experiment set up. (a) Test box and measurement devices in its surroundings, (b) detail of installation of indoor air temperature sensors protected by aluminum cylinders, (c) detail of installation of shielded and ventilated outdoor air temperature sensors.

The thermal transmittance ( $\mathrm{U}$ in $\mathrm{Wm}^{-2} \mathrm{~K}^{-1}$ ) and the solar-energy transmittance ( $\mathrm{g}$, dimensionless) have been considered to characterize the opaque elements (ceiling, floor and walls) from one-dimensional analysis. The overall thermal transmission coefficient $\left(\mathrm{UA}\right.$ in $\left.\mathrm{WK}^{-1}\right)$ and the total solar heat gain factor ( $\mathrm{gA}$ in $\mathrm{m}^{2}$ ), have been considered to characterize the whole building envelope from three-dimensional analysis. The values of the characteristic parameters of the building theoretically calculated, together with the results obtained applying other method for the analysis were used as complement to the validation criteria (Table 1). The maximum deviations for the theoretical values were calculated as the standard deviation among all the average values for winter and summer data 
series due to variations of surface temperature and wind speed, which are minor deviations, as shown in Table 1. The g value is very low. According to [15], it is 0.0060 in average. Taking into account this low value it could lead to an undetectable effect of the solar radiation on the interior surfaces of the opaque walls.

Table 1. Theoretical values of the characteristic parameters and estimated ranges of deviations from their constant values, and values obtained applying other analysis method [31].

\begin{tabular}{lccc}
\hline \multicolumn{1}{c}{ Parameters } & Theoretical Value & Maximum Deviation & $\begin{array}{c}\text { Value from Dynamic } \\
\text { Integrated Method [31] }\end{array}$ \\
\hline U Ceiling $\left(\mathbf{W} / \mathbf{m}^{2} \mathbf{K}\right)$ & 0.476 & $0.003(0.7 \%)$ & $0.50 \pm(1.0 \%)$ \\
U Back $\left(\mathbf{W} / \mathbf{m}^{2} \mathbf{K}\right)$ & 0.476 & $0.003(0.7 \%)$ & $0.45 \pm(0.03 \%)$ \\
U Right Wall $\left(\mathbf{W} / \mathbf{m}^{2} \mathbf{K}\right)$ & 0.476 & $0.003(0.7 \%)$ & $0.45 \pm(2.5 \%)$ \\
U Left Wall $\left(\mathbf{W} / \mathbf{m}^{2} \mathbf{K}\right)$ & 0.476 & $0.003(0.7 \%)$ & $0.45 \pm(1.0 \%)$ \\
UA Whole Box $(\mathbf{W} / \mathbf{K})$ & 4.08 & $0.03(0.7 \%)$ & $4.08 \pm(0.6 \%)$ \\
gA Whole Box $\left(\mathbf{m}^{2}\right)$ & 0.162 & $0.00002(0.01 \%)$ & $0.160 \pm(1.7 \%)$ \\
\hline
\end{tabular}

\subsubsection{Boundary Conditions}

The test campaign was carried out outdoors at the Plataforma Solar de Almeria (PSA), in the south east of Spain $\left(37.1^{\circ} \mathrm{N}, 2.4^{\circ} \mathrm{W}\right)$. The area is rural, and the climate is typically hot and dry in summer and cold in winter; the air temperature presents large oscillations from day to night, with high levels solar radiation and clear sky.

\subsubsection{Conducted Experiments and Data Series}

Several experiments have been conducted under different test conditions to obtain different data series which are suitable to analyze different aspects of the modelling methods. The heating power was supplied by a $100 \mathrm{~W}$ incandescence lamp and the indoor air temperatures have been controlled in order to set the different test conditions. The experiment set up includes a comprehensive set of measurement devices [15]. The following subset of variables has been used for the analysis described in the next sections:

- Indoor air temperature, $T_{i}$, as the average of the two measurements of this variable $T_{i}$ down and $T_{i \_u p}$, shown in Figure $1 b$.

- Outdoor air temperature, $T_{e}$, as the average of the two measurements of this variable $T_{e \_ \text {middle }}$ and $T_{e_{-} \text {down, }}$ shown in Figure $1 \mathrm{c}$.

- Measured heat flux through ceiling, floor and all the opaque walls: $\varphi_{\text {ceiling }}, \varphi_{\text {floor }}, \varphi_{\text {back }}, \varphi_{\text {left }}$ and $\varphi_{\text {right }}$.

- Measured heating power, $P_{\text {heating }}$.

- Measured global vertical solar radiation facing south, $G_{v}$.

The experiments have been designed aiming to produce several data series containing the information required to apply system identification techniques. The phenomena to be characterized must be evident and strong enough for the application of these techniques. In this context, a phenomenon is strong enough when the amplitude of its driving variable is significantly higher than the uncertainty in its measurement. If a driving variable does not fit this requisite, signal to noise is poor, leading to inaccurate parameter estimates. Accordingly:

- To identify the heat transfer coefficient, the test set-up must guarantee strong enough heat loss through the building envelope maximizing the indoor to outdoor air temperature difference, which is the driving variable for this effect.

- To identify the overall gA-value, the solar gains must be strong enough. This is achieved when the test period includes enough sunny days with high levels of solar radiation, which is the corresponding driving variable. 
- To identify dynamic models, the system must be excited by dynamic input signals containing a wide range of frequencies and including the characteristic time constants of the system. The variables involved in the energy balance equations of outdoor tests have a dynamic character, but identification is facilitated by the application of certain power sequences such as the ROLBS [33] etc.

The following issues regarding the experiment set up are also relevant to the identifiability and accuracy of the parameter estimates:

- Heating Power: heating the indoor air is necessary to maximize the indoor to outdoor air temperature difference. Free running tests usually lead to poor signal to noise ratios in the measurements of temperature difference and cause problems with identifiability. Additionally, the heating power must be strong enough because it is a relevant variable to the energy balance equation that must be used for the analysis.

- Homogeneity of the indoor air temperature: the solar radiation and the heating systems are heating sources that can produce some inhomogeneity to the indoor air temperature which contribute to the uncertainty of the parameter estimates. A mini fan has been used to improve the air temperature homogeneity. A device with very small ventilation power has been chosen to avoid perturbations in the interior convection coefficients.

- Sampling frequency: the sampling theorem must be fulfilled in the raw data as well as in any resampling applied in the pre-processing phase. The sampling frequency must be at least twice the frequency of the variable which is being measured.

According to all these issues three data series corresponding to different periods have been considered. One-minute sampling interval has been set. This sampling interval guarantees that the raw data fulfil the sampling theorem. The main differences among the three periods concerns to the heating power and indoor temperature settings:

- Series 16: 6 December 2013 to 17 December 2013 (12 days). This series includes one ROLBS power sequence and was mainly designed to optimize the test conditions to the application of the system identifications techniques.

- Series 17: 18 December 2013 to 26 December 2013 (9 days). Aiming to reproduce as possible a coheating test, but setting the indoor air temperature set point to $35^{\circ} \mathrm{C}$. This test sequence was designed in order to have a reference analysis according as much as possible to the traditional coheating test, and also to explore the application of steady-state approaches and also to analyze the capability to apply the system identification techniques to this type of tests. This series is also useful to analyze causality issues and different variables as the input signal. It must be observed that this test is not identical to the coheating test described in the literature [17]. It is a bit modified taking into account the given boundary conditions: in winter the indoor air temperature cannot be maintained at a constant $25^{\circ} \mathrm{C}$ because the low position of the sun produces a strong global solar radiation incident on the window (Figure 2e). Consequently, the indoor air temperature shows some dynamic behavior with overheating intervals (Figure 2d) even raising the set point to $35^{\circ} \mathrm{C}$.

- Series 18: 27 December 2013 to 7 January 2014 (12 days): also aiming to reproduce as possible a Coheating test, but in this case setting the indoor air temperature set point to $21^{\circ} \mathrm{C}$, intending to emulate the comfort zone in an in-use building. These more realistic conditions are set in order to explore the possibilities to apply these identification techniques to in-use buildings using data recorded by its on-board monitoring systems. These test conditions are also interesting to analyze causality issues and different variables as output signals. In this case, the low level of the indoor to outdoor air temperature difference increases the difficulty to identify the UA value. Additionally, the contribution of the solar radiation to the space heating makes it impossible to maintain a constant indoor air temperature. This effect, clearly seen from the observation of Figure 2e,f, is stressing the need to apply dynamic techniques for the analysis. 


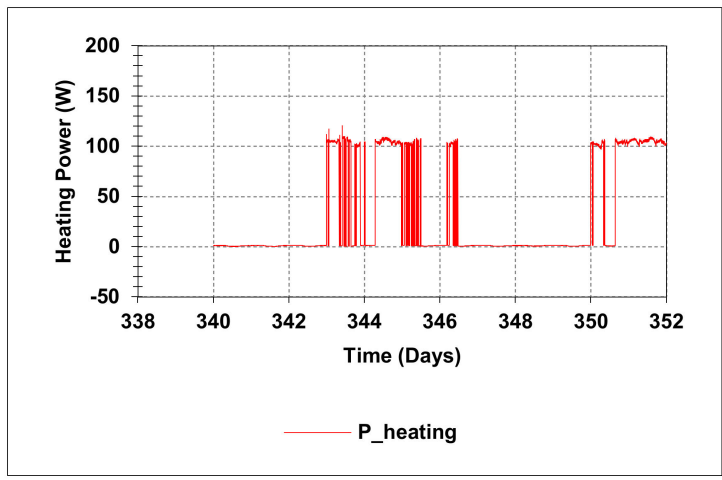

(a)

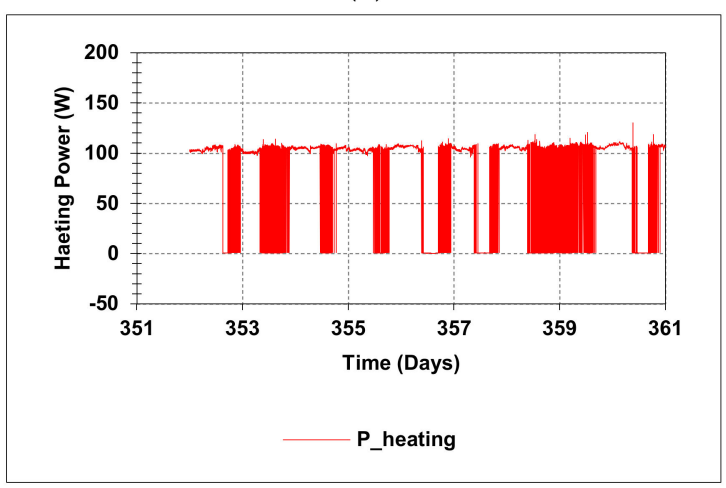

(c)

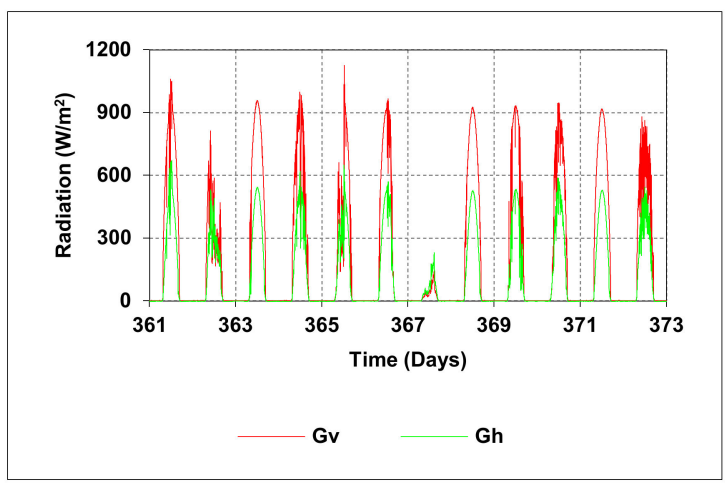

(e)

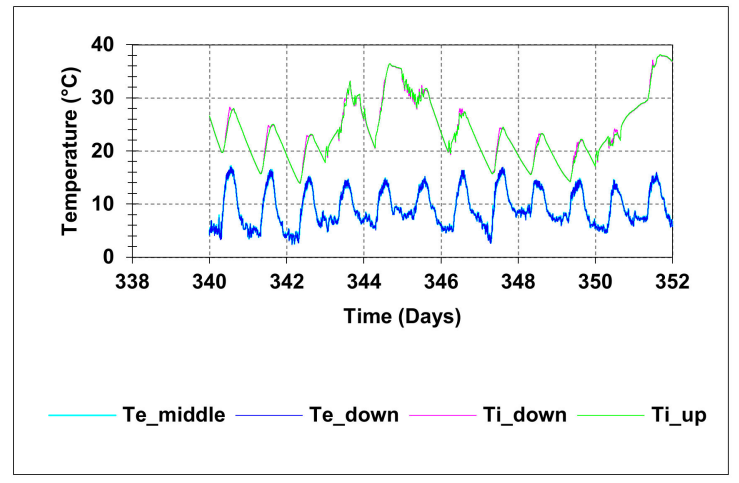

(b)

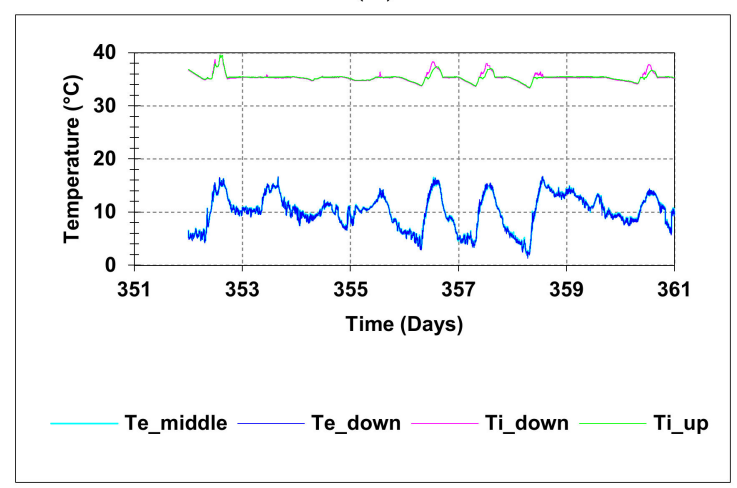

(d)

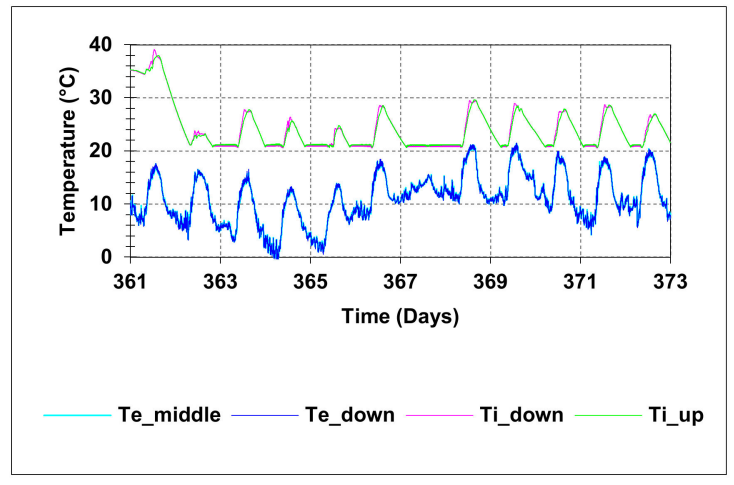

(f)

Figure 2. Data overview where $P_{\text {heating }}$ is the heating Power; $G_{v}$ and $G_{h}$ are the vertical and the horizontal global solar radiation, $T_{i_{-} \text {down }}$ and $T_{i_{-} \text {up }}$ are the two measurements of the indoor air temperature, $T_{e_{-} \text {middle }}$ and $T_{e_{-} \text {down }}$ are the two measurements of the outdoor air temperatures. (a) Heating power. Series 16, (b) indoor and outdoor air temperatures. Series 16, (c) heating power. Series 17, (d) indoor and outdoor air temperatures. Series 17, (e) vertical and horizontal global solar radiation. Series 18, (f) indoor and outdoor air temperatures. Series 18.

Finally, the consecutive records available in these data series have been merged in one data series and then this full data series has been split in three series with identical length. The analysis has been done using the resulting four data series, named as:

- Series a: 6 December 2013 to 16 December 2013 (11 days). The test conditions in this series are dominated by the test conditions in series 16 , with a ROLBS power sequence.

- Series b: 17 December 2013 to 27 December 2013 (11 days). The test conditions in this series are dominated by the test conditions in series 17 , mainly with $35^{\circ} \mathrm{C}$ set point for the indoor air temperature which is mainly constant. 
- Series c: 28 December 2013 to 7 January 2014 (11 days): The test conditions in this series are dominated by the test conditions in series 18 , mainly with $21^{\circ} \mathrm{C}$ set point for the indoor air temperature trying to maintain a constant indoor air temperature which actually has a dynamic behavior.

- Series d: 6 December 2013 to 7 January 2014 (33 days), which is the combination of series 16, 17 and 18 , therefore including a rich diversity of test conditions.

\subsection{Data Analysis and Modelling Methodology}

The subsequent subsections describe the following issues of the methodology that has been applied: First, the dynamic RC modelling approach is briefly presented (in Section 2.2.1). The criteria to assess performance of the models and the validity of the results are presented (in Section 2.2.2). Then the application of this methodology to the ceiling, floor, opaque walls (in Section 2.2.3) and the whole building (in Section 2.2.4) is described. Afterwards, some models including modelling of some effects driven by unmeasured variables are considered (in Section 2.2.5).

Several candidate models have been considered. All these candidate models have been constructed translating the physical features of the considered thermal systems into RC model structures. Simplifications, in which validity was demonstrated in previous work [31], were taken into account to construct these RC models. Accordingly, the starting points of this work are the results and conclusions reported in [31]. This work explores the capabilities of RC models to improve the results of that work analyzing the following aspects:

- Further analysis of the influence of the solar radiation that is transmitted through the opaque walls versus the performance of the models including this effect. The work reported in [31] concluded that including the solar radiation in the models of the opaque walls does not improve the accuracy of the $U$ value estimates. However, a model including a y-intercept was identified as the best model among the considered candidate models. The y-intercept was interpreted as a representation of the sum of the effects that were not included explicitly in the model. This issue induced us to carry out further analysis reconsidering the effect of the solar radiation applying the RC approach described in this paper.

- Other effects such as dependencies on wind speed, surface and fabric temperatures have been disregarded taking into account the conclusions of the work reported in [31].

- Several options modelling relevant effects using unmeasured variables in order to evaluate the feasibility to reduce the cost and intrusiveness of the measurement devices required us to obtain accurate results. These options were not considered in [31]. However other works have demonstrated the usefulness of modelling several effects which are driven by unmeasured variables [34,35].

Additionally, the following issues of the RC modelling approach have been investigated along the application of this method to the particular case study considered in this work:

- Reduction of the test period regarding the test period required us to obtain accurate results applying the dynamic integrated method applied in [31].

- The optimum number of nodes required to represent the thermal systems.

- The assignment of inputs and outputs.

- The performance of the models using data recorded under different test conditions.

\subsubsection{RC Models}

$R C$ models are used for obtaining the $U$ value of the opaque walls and the UA value and gA value of the whole building. These models use an electrical analogy representing the thermal system to obtain the required parameters. The software tool LORD [30] has been used to identify the parameters of these models. Physical criteria have been combined with this modelling approach to obtain these coefficients 
and also to validate the results. This applied approach is based on energy balances, constructed from the main heat transfer contributions that are identified and modelled.

First, the $U$ values of the opaque walls, ceiling and floor were obtained by a one-dimensional analysis based on direct measurement of heat flux through the interior surfaces. The main focus of this analysis was determining the optimum number of nodes to represent the opaque walls. Afterwards, a three-dimensional analysis based on the energy balance on the air volume confined by the building envelope, was applied to estimate the overall UA and gA values of the whole building envelope. The data series $a, b, c$ and $d$ recorded under different test conditions as well as the results obtained in previous work, applying a different method [31] and also the target design values, were used to analyze the robustness of the results.

\subsubsection{Assessment of the Validity of the Results}

The performance of the candidate modes to give accurate estimates of the required characteristic parameters was evaluated considering these aspects:

- The physical coherence of the results obtained using different data series recorded under very different test conditions. The uncertainty related to the spread in each parameter was quantified through the following parameter [36] and its minimization was used as a criterion for consistency:

$$
\sigma_{X}=\frac{X_{\max }-X_{\min }}{\sqrt{12}}
$$

where $X$ represents the parameter estimate that can be $\mathrm{U}, \mathrm{g}, \mathrm{UA}$ or $\mathrm{gA} . X_{\max }$ and $X_{\min }$ are, respectively, the maximum and minimum among the $X$ estimates obtained from all the available data series; and $\sigma_{x}$ is the error obtained as the squared root of the variance estimate assuming a rectangular distribution [36] for the parameter $X$.

- The average of the residuals: Considering the minimization of the difference between measured output variable and model output, as indicator of good model performance. The value of this indicator is considered good enough when it is in the range of the uncertainty of the measurement of the model output.

- The agreement with the theoretical target values that are reported in Section 2.1.1. These values are considered reliable references and are relevant complements to the validation criteria, taking into account the simplicity and the detailed and accurate knowledge of the construction.

- The agreement with the results obtained by the application of other methods [31].

The systematic analysis and discussion of the quality of the results obtained from the different candidate models has been assisted by plots of the proposed indicators versus the different modelling options.

\subsubsection{Modelling of the Ceiling, Opaque Walls and Floor}

The analysis to obtain the $U$ value of the opaque walls, ceiling and floor was based on the one-dimensional energy balance equation on the corresponding interior surface. This energy balance was referred to the net heat flux density measured on this surface. Several candidate models were constructed based on different approximations for these effects and considering these contributions:

- Heat losses through the wall driven by the indoor to outdoor air temperature difference. A constant $\mathrm{U}$ value is assumed to characterize this effect. As explained before, variations of this parameter due to other effects have been disregarded.

- Solar gains driven by the solar radiation. Different candidate models that exclude and include this effect were constructed, considering that this contribution could be a bit relevant or negligible to the net heat flux through the opaque walls, ceiling and floor. The global solar radiation measured 
on the corresponding exterior surface, multiplied by an unknown constant $g$ value, was considered in those candidate models including this contribution.

Taking into account these contributions, introducing $c$ as the effective heat capacity of the wall and $T_{w}$ as its temperature, the one-dimensional energy balance equation on the interior surface of each opaque wall, with all the terms in $\mathrm{W} / \mathrm{m}^{2}$, is written as:

$$
\varphi=c \frac{d T_{w}}{d t}+U\left(T_{i}-T_{e}\right)-g G,
$$

The RC candidate models representing this energy balance in each opaque wall were constructed linking indoor and outdoor air temperatures by one branch with several capacitors and resistances in series (Figure 3a) as explained hereafter:

- Models with $\mathrm{n}$ nodes and being $\mathrm{n}$ from 3 to 7 were considered, in order to analyze different distributions of thermal mass along the thickness of the walls. To avoid over-parameterization, symmetry was assumed. $\mathrm{H}_{1-2}=\mathrm{H}_{(\mathrm{n}-1)-n} ; \mathrm{C}_{2}=\mathrm{C}_{\mathrm{n}-1} ; \mathrm{H}_{2-3}=\mathrm{H}_{(\mathrm{n}-2)-(\mathrm{n}-1)} ; \mathrm{C}_{3}=\mathrm{C}_{\mathrm{n}-2}$; etc.

- The heat flux multiplied by a parameter $\left(\mathrm{A}_{n}\right)$ which is fixed to 1 , is linked to node $n$.

- The outdoor air temperature $\left(T_{e}\right)$ is linked to node 1 .

- The indoor air temperature $\left(T_{i}\right)$ is linked to node $\mathrm{n}$.

- Models including and non-including the solar radiation were evaluated as discussed in previous paragraphs. For models including the solar radiation, it is multiplied by an unknown parameter $\left(\mathrm{A}_{2}\right)$ and linked to node 2.

- The indoor air temperature $\left(T_{i}\right)$ and the heat flux through the internal surface of the wall $(\varphi)$ were considered as alternative outputs to the models. In principle the selection of the model output must be based on causality, but both options were analyzed when these variables do not evidence clearly which one should be chosen as output according to this criterion.

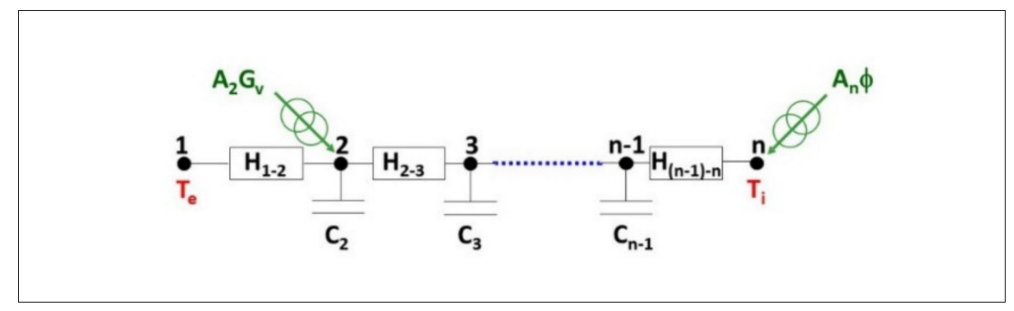

(a)

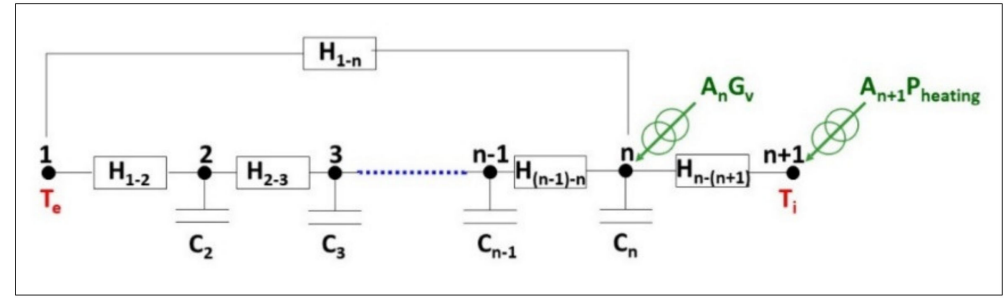

(b)

Figure 3. RC models considered for the analysis. The blue dots indicate the different candidate models adding resistances and capacitances where $\mathrm{n}$ is 3 to 7 . (a) One-dimensional analysis of the opaque walls. With $A_{n}$ fixed to 1 , and $C_{1}=C_{n}=0$. (b) Three-dimensional analysis of the whole building. With $A_{n}$ identified by the model and $A_{n+1}$ fixed to 1 , and $C_{1}=C_{n+1}=0$.

First, a systematic analysis of the ceiling considering all these options and their combinations was carried out. Once the best model for the ceiling was identified among all the candidate models considered, the $\mathrm{U}$ value of floor and left, right, back walls was obtained using the best model found for the ceiling taking into account that all these opaque components were almost identical. The following 
measurements of solar radiation were used: the horizontal global solar radiation for the ceiling, the north vertical global solar radiation for the back wall, and the south vertical global solar radiation for the floor, right and left walls.

Once we identified the best model representing the opaque walls, we analyzed the effect of the length of the test period on the accuracy of the results. This model has been used to obtain the $U$ value of the ceiling, floor and opaque walls for different test lengths from 1 to 10 days.

\subsubsection{Modelling of the Whole Building}

The analysis to obtain the UA and gA of the whole box envelope was based on the three-dimensional energy balance equation on the air volume confined by the building envelope. This energy balance refers to the energy supplied and removed from this volume. Several candidate models were constructed based on different approximations for these effects and considering these contributions:

- Heat supplied to the room by the heating system, $P_{\text {heating. }}$.

- Heat losses through the building envelope driven by the indoor to outdoor air temperature difference. A constant UA value is assumed. Variations of this parameter with wind speed and outdoor surface temperature have been disregarded taking into account the conclusions from a previous work [31].

- Solar gains driven by the solar radiation. Modelled as an unknown constant gA value multiplied by the measured global vertical solar radiation. This effect is modelled assuming that the main contribution of the solar radiation to the energy balance in the room is caused by the global vertical solar radiation incident on the window.

- Air leakage. All the candidate models have been constructed under the hypothesis that this effect is negligible, taking into account that the construction is known to be very tight. The results reported in [31] corroborate this assumption.

Taking into account these contributions and introducing $C$ as the effective heat capacity of the room, the three-dimensional energy balance equation on the air volume confined by the building envelope, with all the terms in $\mathrm{W}$, is written as:

$$
P_{\text {heating }}=C \frac{d T_{i}}{d t}+U A\left(T_{i}-T_{e}\right)-g A G_{v},
$$

The RC candidate models representing this energy balance in the air volume confined by the building envelope were constructed linking the indoor and outdoor air temperatures by the element constituted by several capacitors and resistances (Figure $3 b$ ) as explained hereafter:

- A branch representing the opaque walls. Candidate models with 3 to 7 nodes in this branch were considered, in order to analyze the suitability of modelling different distributions of thermal mass along the thickness of these walls. To avoid over-parameterization, symmetry has been assumed. $\mathrm{H}_{1-2}=\mathrm{H}_{(\mathrm{n}-1)-\mathrm{n}} ; \mathrm{C}_{2}=\mathrm{C}_{\mathrm{n}-1} ; \mathrm{H}_{2-3}=\mathrm{H}_{(\mathrm{n}-2)-(\mathrm{n}-1)} ; \mathrm{C}_{3}=\mathrm{C}_{\mathrm{n}-2}$; etc.

- A parallel branch, consisting in just a thermal resistance, representing a faster heat transmission through the building envelope, mainly due to the window.

- The outdoor air temperature $\left(T_{e}\right)$ is linked to node 1 .

- The indoor air temperature $\left(T_{i}\right)$ is linked to node $n$.

- All the candidate models include the south vertical solar radiation $\left(G_{v}\right)$ taking into account that the facing south windows provoke a relevant contribution to the energy supplied to the room. It is multiplied by an unknown parameter $\left(A_{n}\right)$ and linked to node $n$.

- Node $\mathrm{n}+1$ is linked to node $\mathrm{n}$ by a conductance that is fixed to a large value (such that $\left.\left(1 / H_{n+1-n} \rightarrow 0\right)\right)$. The heating power $\left(P_{\text {heating }}\right)$ multiplied by a parameter $\left(A_{n+1}\right)$ fixed to 1 is linked to node $n+1$. This makes node $n+1$ equivalent to node $n$, but it is necessary because the tool used to identify the considered models (LORD, $[30,37]$ ) allows just one link of heat flux per node. 
- The indoor air temperature $\left(T_{i}\right)$ and the heating power $\left(P_{\text {heating }}\right)$ were considered as alternative outputs to the models. The issues that justify the consideration of these two options for the output are the analogous to those mentioned in Section 2.2.3 for the opaque walls.

A systematic analysis of the whole box considering all these options and their combinations was carried out.

Once identified the best model representing the whole building, the effect of the length of the test period on the accuracy of the results has been analyzed. This model has been applied to obtain the UA and $\mathrm{gA}$ value of the whole building for different test lengths from 1 to 10 days.

\subsubsection{Models Including Effects Driven by Unmeasured Variables}

Once the best model was identified among all the candidate models considered, several options modelling the relevant effects using unmeasured variables were proposed and evaluated in order to study the feasibility to reduce the cost and intrusiveness of the measurement devices required to obtain accurate results. The following candidate models were considered:

- Model 1: using a synthetic variable, instead of the measured $G_{v}$, calculated according the following expression trying to emulate the shape of the actual vertical global solar radiation:

$$
G_{v_{-} \text {synthetic }}=\left\{\begin{array}{c}
\cos (2 \pi t+\pi) ; I f G_{h}>1 \mathrm{~W} / \mathrm{m}^{2} \\
0 ; I f G_{h} \leq 1 \mathrm{~W} / \mathrm{m}^{2}
\end{array},\right.
$$

This strategy improves cost effectiveness as far as it can avoid the use of a pyranometer, specifically installed for this analysis, measuring the global solar radiation on the orientation where the building has relevant glassing surfaces. It can be applied in any the following cases:

1. When the horizontal global solar radiation is available, that is more standardized than having it in any vertical surface.

2. When no measurement of solar radiation is available, but the time of sunrise and sunset are known, which is relatively easy for a given location.

- Model 2: using a synthetic outdoor air temperature, instead of the measured $T_{e}$, calculated according to the following expression:

$$
T_{e_{-} s y n t h e t i c}=8.48{ }^{\circ} \mathrm{C}\left\{1+\frac{\cos [2 \pi(t-\Delta t)+\pi]}{2}\right\},
$$

where $8.48^{\circ} \mathrm{C}$ is the average outdoor air temperature according to the Typical Meteorological Year (TMY) that was available for the location as reported in $[6,38] . \Delta t$ is a two-hour delay observed between the solar radiation and the outdoor air temperature. This strategy offers the possibility for a cost reduction when the $T_{e}$ corresponding to the TMY of the place is available.

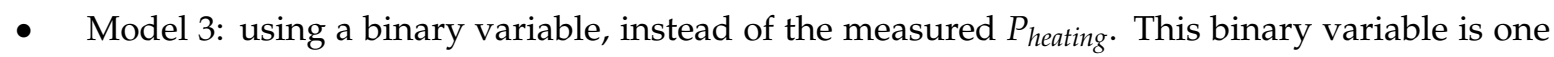
when the heating is on and zero when the heating is off. The coefficient $\mathrm{A}_{4}$ was fixed to the average of the heating power when it is on. In practice this would be equivalent to having a record of the status of the heating system (on or off) along the experiment and the measurement of the heating power supplied without being necessary any devices for its continuous measurement. This option represents a moderate cost reduction as far as continuous measurement of heating power is avoided, but it requires the continuous measurement of the status of heating system which is simpler and cheaper than a continuous accurate measurement of the heating power.

- Model 4: the only difference between this model and Model 3 is that, in Model 4, the parameter $\mathrm{A}_{4}$ is an identifiable parameter instead of the fixed value used in Model 3. 
- Model 5: using the set point indoors air temperature, instead of the measured $T_{i}$. This option allows us to avoid the measurement of the indoor air temperature. This strategy is useful to reduce the cost of the experiment as well as its intrusiveness.

\section{Results and Discussion}

This section presents the results obtained using all the candidate models and discusses their validity.

\subsection{Analysis of the Opaque Walls}

The results given by the different candidate models considered for the opaque walls, and the validity of these results are presented and discussed in Sections 3.1.1 and 3.1.2.

\subsubsection{The Ceiling}

The results obtained using the different candidate models are presented in Figure 4 and Tables 2-5. These tables and figure indicate that the three nodes models present a very bad performance taking into account the large spread observed between the results obtained from different data series, the large average value of the residual and the $U$ value estimates which are far from the target theoretical values and also far from the values obtained applying other methods. Attending to the same criteria, a significant improvement is observed in the four nodes models. However, scarce variations are observed when the number of nodes is increased. In some cases, the tendencies of these minor variations regarding the four nodes models are towards worse performance.

Focusing on the four nodes models and attending to the spread of the results using different data series, the model with $T_{i}$ as output shows slightly smaller spread in the results than using $\varphi_{\text {ceiling }}$ as output for the same model. Models including solar radiation do not show improvement regarding those not including it. The others validity criteria do not show significant differences.

Figure $5 \mathrm{c}$ and Tables 4 and 5 show that the $g$ values identified from the models including the solar radiation are very low with relatively large uncertainties which indicates a poor identification of this parameter due to its low value according to Section 2.1.1, corroborating its negligibility. This issue corroborates why the models including the solar radiation are not improved.

According to these issues, the $U$ value estimate obtained from the four nodes model, not including solar radiation and using the indoor air temperature as output has been chosen (Figure $4 \mathrm{~b}$ and Table 2).

\subsubsection{Floor, Back, Right and Left Walls}

The results obtained using the four nodes model for the floor, back, right and left walls are summarized in Figure 5 and Tables 6-8. The $U$ value estimates present better performance when the solar radiation is not included (Figure 5a,b, and Tables 6 and 7). The g value estimates when models include the solar radiation, are very low with large uncertainties (Figure $5 \mathrm{c}$ and Table 8). This behavior was also observed for the ceiling, which makes sense taking into account that all these opaque elements are identical, concluding that including the solar radiation also has a negative effect on the performance of the models for the floor and opaque walls. The results obtained with the model that do not include the solar radiation present very good agreement with the theoretical values and also with the results obtained using other different method reported in [31] (Table 1).

\subsubsection{Model Performance for Different Length of Test Period}

Considering the results for the ceiling and back wall, very little variation in the accuracy of the $\mathrm{U}$ value estimates for the different lengths of test period is observed. Attending to the spread in the $U$ value estimates for different data series, a slight improvement is observed for a six-day test period which is maintained similar for larger test periods (Figure 6a and Table 9). The average of the residuals does not show relevant differences for the different lengths of test period. These residuals are low and in the range of the uncertainty of the measurement of the output variable. 


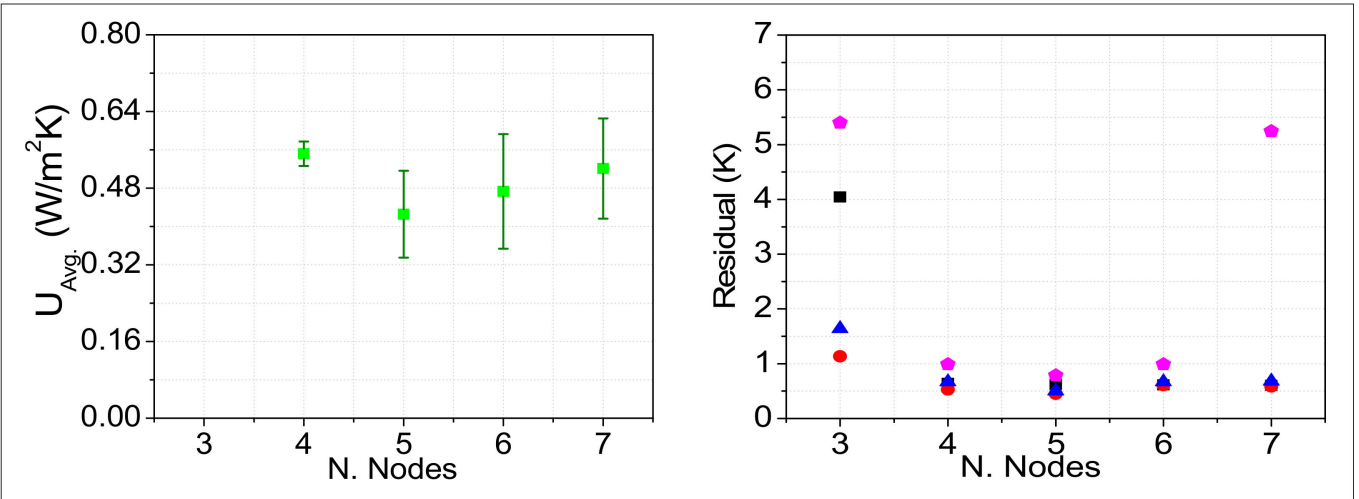

(a)
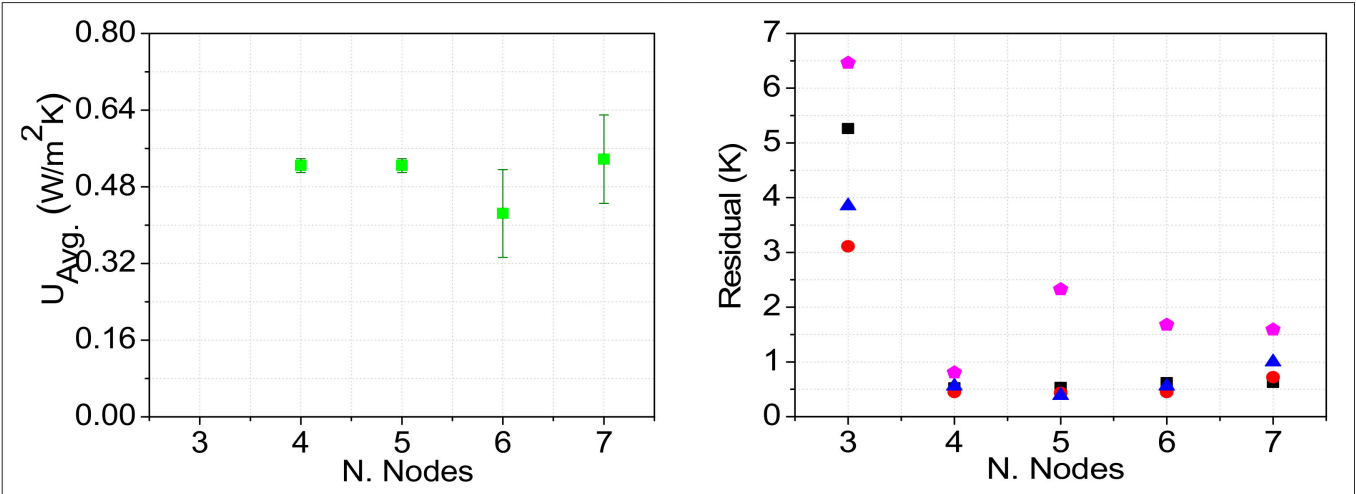

(b)
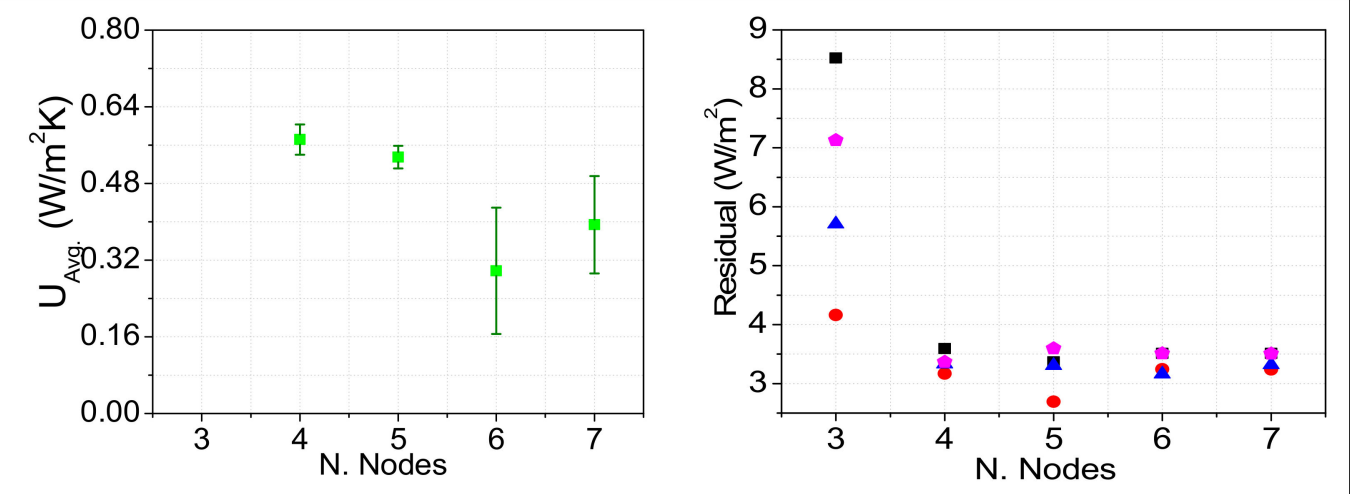

(c)
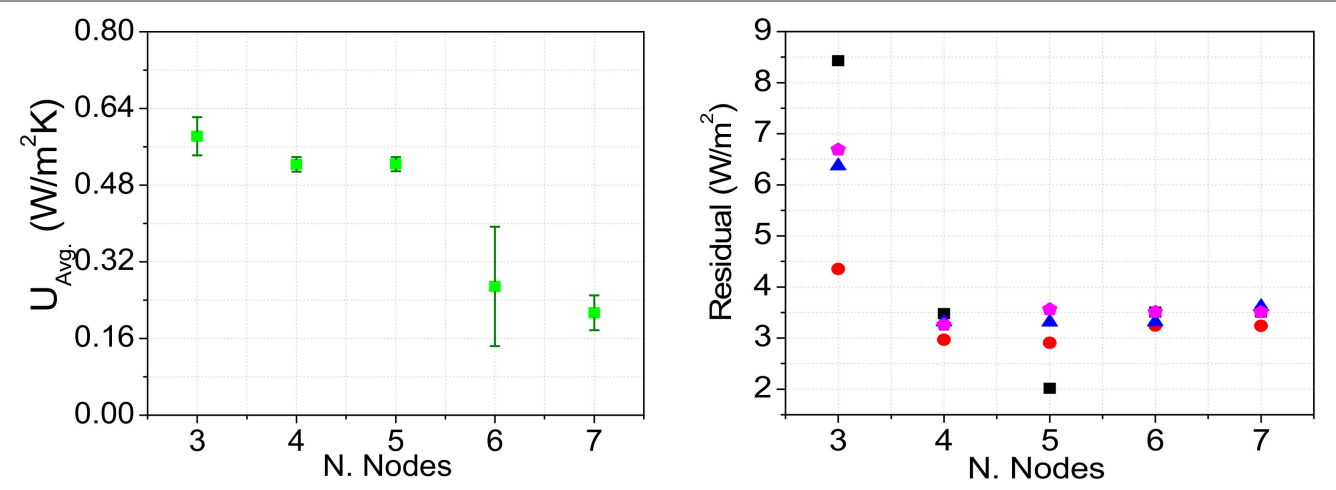

(d)

Figure 4. Ceiling. Results obtained using different candidate models. Left: average of U value for series $\mathrm{a}, \mathrm{b}$ and $\mathrm{c}$. Right: residuals for series a in black, series $\mathrm{b}$ in red, series $\mathrm{c}$ in blue and pink for the full data series d. (a) Including solar radiation. Output: $T_{i},(\mathbf{b})$ not including solar radiation. Output: $T_{i}$, (c) including solar radiation. Output: $\varphi_{\text {ceiling, }}(\mathbf{d})$ not including solar radiation. Output: $\varphi_{\text {ceiling }}$. 
Table 2. Ceiling. U value. Summary of the results using models that do not include solar radiation. Output: $T_{i}$. Where eu is the error and $\mathrm{R}$ is the average of the residuals given by LORD for each data series.

\begin{tabular}{|c|c|c|c|c|c|c|c|c|c|c|c|c|c|c|c|}
\hline \multirow[b]{2}{*}{$\begin{array}{c}\mathbf{N}^{\mathrm{er}} \\
\text { Nodes }\end{array}$} & \multicolumn{3}{|c|}{$\rightarrow-$ Series a } & \multicolumn{3}{|c|}{- Series b } & \multicolumn{3}{|c|}{- -Series c } & \multicolumn{3}{|c|}{- Series d } & \multicolumn{3}{|c|}{ Series $a, b, c$} \\
\hline & $\begin{array}{c}U \\
\left(W / m^{2} K\right)\end{array}$ & $\begin{array}{l}\mathrm{e}_{\mathrm{U}} \\
(\%)\end{array}$ & $\begin{array}{c}\mathrm{R} \\
(\mathrm{K})\end{array}$ & $\begin{array}{c}\mathrm{U} \\
\left(\mathrm{W} / \mathrm{m}^{2} \mathrm{~K}\right)\end{array}$ & $\begin{array}{c}\mathrm{e}_{\mathrm{U}} \\
(\%)\end{array}$ & $\begin{array}{c}\mathrm{R} \\
(\mathrm{K})\end{array}$ & $\underset{\left(W / m^{2} K\right)}{U}$ & $\begin{array}{l}\mathrm{e}_{\mathrm{U}} \\
(\%)\end{array}$ & $\begin{array}{c}R \\
(\mathrm{~K})\end{array}$ & $\underset{\left(W / m^{2} K\right)}{U}$ & $\begin{array}{l}\mathrm{e}_{\mathrm{U}} \\
(\%)\end{array}$ & $\begin{array}{c}\mathrm{R} \\
(\mathrm{K})\end{array}$ & $\begin{array}{c}U_{\text {avg }} \\
\left(W / m^{2} K\right)\end{array}$ & $\begin{array}{c}\sigma_{U} \\
\left(W / m^{2} K\right)\end{array}$ & $\begin{array}{l}\sigma_{U} \\
(\%)\end{array}$ \\
\hline 3 & 1.47 & 7.2 & 5.26 & 0.93 & 0.1 & 3.11 & 1.42 & 0.8 & 3.85 & 0.59 & - & 6.46 & 1.27 & 0.16 & 12.4 \\
\hline 5 & 0.53 & 0.3 & 0.53 & 0.50 & 0.1 & 0.43 & 0.55 & 0.3 & 0.39 & 0.27 & 0.3 & 2.33 & 0.52 & 0.01 & 2.8 \\
\hline 6 & 0.23 & 0.2 & 0.62 & 0.50 & 0.005 & 0.45 & 0.55 & 0.1 & 0.56 & 0.24 & 0.1 & 1.68 & 0.42 & 0.09 & 21.6 \\
\hline 7 & 0.34 & 0.6 & 0.62 & 0.66 & 0.3 & 0.72 & 0.61 & 100 & 1.00 & 0.24 & 0.2 & 1.59 & 0.54 & 0.09 & 17.2 \\
\hline
\end{tabular}

Table 3. Ceiling. U value. Summary of the results using models that include solar radiation. Output: $T_{i}$. Where eU is the error and $\mathrm{R}$ is the average of the residuals given by LORD for each data series.

\begin{tabular}{|c|c|c|c|c|c|c|c|c|c|c|c|c|c|c|c|}
\hline \multirow[b]{2}{*}{$\begin{array}{c}\mathrm{N}^{\mathrm{er}} \\
\text { Nodes }\end{array}$} & \multicolumn{3}{|c|}{$\rightarrow-$ Series a } & \multicolumn{3}{|c|}{- Series b } & \multicolumn{3}{|c|}{$\triangle-$ Series c } & \multicolumn{3}{|c|}{ - Series d } & \multicolumn{3}{|c|}{ Series $a, b, c$} \\
\hline & $\begin{array}{c}U \\
\left(W / m^{2} K\right)\end{array}$ & $\begin{array}{l}e_{U} \\
(\%)\end{array}$ & $\begin{array}{c}R \\
(\mathrm{~K})\end{array}$ & $\begin{array}{c}U \\
\left(W / m^{2} K\right)\end{array}$ & $\begin{array}{l}\mathrm{e}_{\mathrm{U}} \\
(\%)\end{array}$ & $\begin{array}{c}R \\
(\mathbf{K})\end{array}$ & $\begin{array}{c}U \\
\left(W / m^{2} K\right)\end{array}$ & $\begin{array}{l}\mathrm{e}_{\mathrm{U}} \\
(\%)\end{array}$ & $\begin{array}{c}R \\
(\mathrm{~K})\end{array}$ & $\begin{array}{c}U \\
\left(W / m^{2} K\right)\end{array}$ & $\begin{array}{l}\sigma_{U m} \\
(\%)\end{array}$ & $\begin{array}{c}R \\
(\mathbf{K})\end{array}$ & $\begin{array}{c}U_{\text {avg }} \\
\left(W / \mathrm{m}^{2} \mathrm{~K}\right)\end{array}$ & $\begin{array}{c}\sigma_{U} \\
\left(W / m^{2} K\right)\end{array}$ & $\begin{array}{l}\sigma_{U} \\
(\%)\end{array}$ \\
\hline 4 & 0.56 & 0.3 & 0.64 & 0.51 & 0.1 & 0.53 & 0.59 & 0.2 & 0.67 & 0.52 & 0.005 & 0.99 & 0.55 & 0.03 & 4.6 \\
\hline 5 & 0.23 & 0.3 & 0.62 & 0.50 & 0.005 & 0.45 & 0.55 & 0.005 & 0.50 & 0.51 & 0.005 & 0.79 & 0.43 & 0.09 & 21.3 \\
\hline 6 & 0.21 & 0.3 & 0.61 & 0.62 & 14.7 & 0.61 & 0.59 & 0.3 & 0.67 & 0.52 & 0.3 & 0.99 & 0.47 & 0.12 & 25.3 \\
\hline
\end{tabular}

Table 4. Ceiling. g value. Summary of the results using models that include solar radiation. Output: $T_{i}$. Where eg is the error and $\mathrm{R}$ is the average of the residuals given by LORD for each data series.

\begin{tabular}{|c|c|c|c|c|c|c|c|c|c|c|c|c|c|c|c|}
\hline \multirow[b]{2}{*}{$\begin{array}{c}\mathrm{N}^{\mathrm{er}} \\
\text { Nodes }\end{array}$} & \multicolumn{3}{|c|}{$\rightarrow-$ Series a } & \multicolumn{3}{|c|}{- -Series b } & \multicolumn{3}{|c|}{- -Series c } & \multicolumn{3}{|c|}{- Series d } & \multicolumn{3}{|c|}{ Series $a, b, c$} \\
\hline & $\begin{array}{c}g \\
(-)\end{array}$ & $\begin{array}{c}\mathrm{e}_{\mathrm{g}} \\
(\%)\end{array}$ & $\begin{array}{c}\mathrm{R} \\
(\mathrm{K})\end{array}$ & $\begin{array}{c}g \\
(-)\end{array}$ & $\begin{array}{c}\mathbf{e}_{\mathrm{g}} \\
(\%)\end{array}$ & $\begin{array}{c}R \\
(\mathrm{~K})\end{array}$ & $\begin{array}{c}g \\
(-)\end{array}$ & $\begin{array}{c}\mathbf{e}_{\mathrm{g}} \\
(\%)\end{array}$ & $\begin{array}{c}\mathrm{R} \\
(\mathrm{K})\end{array}$ & $\underset{(-)}{g}$ & $\begin{array}{c}\mathrm{e}_{\mathrm{g}} \\
(\%)\end{array}$ & $\begin{array}{c}R \\
(\mathrm{~K})\end{array}$ & $\underset{(-)}{g_{\text {avg }}}$ & $\begin{array}{l}\sigma_{g} \\
(-)\end{array}$ & $\begin{array}{c}\sigma_{\mathrm{g}} \\
(\%)\end{array}$ \\
\hline 4 & 0.007 & 0.005 & 0.64 & 0.007 & 0.005 & 0.53 & 0.007 & 0.005 & 0.67 & 0.007 & 0.005 & 0.99 & 0.007 & 0 & 0 \\
\hline 5 & - & - & 0.62 & - & - & 0.45 & - & - & 0.50 & - & - & 0.79 & - & - & - \\
\hline 6 & 0.007 & 27.2 & 0.61 & 0.067 & 58.7 & 0.61 & 0.007 & 0.005 & 0.67 & 0.007 & 0.005 & 0.99 & 0.027 & 0.017 & 64.2 \\
\hline 7 & 0.007 & 1.4 & 0.60 & 0.067 & 5.5 & 0.59 & 0.007 & 0.005 & 0.68 & 0.007 & 22.8 & 5.25 & 0.027 & 0.017 & 64.2 \\
\hline
\end{tabular}


Table 5. Ceiling. g value. Summary of the results using models that include solar radiation. Output: $\varphi$. Where $\mathrm{e}_{\mathrm{g}}$ is the error and $\mathrm{R}$ is the average of the residuals given by LORD for each data series.

\begin{tabular}{|c|c|c|c|c|c|c|c|c|c|c|c|c|c|c|c|}
\hline \multirow[b]{2}{*}{$\begin{array}{c}\mathbf{N}^{\mathrm{er}} \\
\text { Nodes }\end{array}$} & \multicolumn{3}{|c|}{$\rightarrow-$ Series a } & \multicolumn{3}{|c|}{- Series b } & \multicolumn{3}{|c|}{- -Series c } & \multicolumn{3}{|c|}{- Series d } & \multicolumn{3}{|c|}{ Series $a, b, c$} \\
\hline & $\underset{(-)}{g}$ & $\begin{array}{c}e_{g} \\
(\%)\end{array}$ & $\begin{array}{c}R \\
\left(W / m^{2}\right)\end{array}$ & $\underset{(-)}{g}$ & $\begin{array}{c}e_{g} \\
(\%)\end{array}$ & $\underset{\left(W / m^{2}\right)}{R}$ & $\underset{(-)}{g}$ & $\begin{array}{c}e_{g} \\
(\%)\end{array}$ & $\underset{\left(W / m^{2}\right)}{R}$ & $\underset{(-)}{g}$ & $\begin{array}{c}e_{g} \\
(\%)\end{array}$ & $\begin{array}{c}R \\
\left(W / m^{2}\right)\end{array}$ & $\underset{(-)}{\text { gavg }}$ & $\begin{array}{l}\sigma_{g} \\
(-)\end{array}$ & $\begin{array}{c}\sigma_{\mathrm{g}} \\
(\%)\end{array}$ \\
\hline 4 & 0.006 & 8.3 & 3.59 & 0.009 & 0.6 & 3.17 & 0.01 & 2.3 & 3.33 & 0.006 & 0.1 & 3.37 & 0.008 & 0.001 & 13.9 \\
\hline 5 & - & - & 3.37 & - & - & 2.69 & 0.004 & 8.7 & 3.31 & - & - & 3.60 & 0.004 & 0 & - \\
\hline 6 & 0.002 & 100 & 3.51 & 0.001 & 100 & 3.24 & 0.003 & 3.8 & 3.16 & 0.002 & 14.9 & 3.51 & 0.002 & 0.001 & 28.9 \\
\hline 7 & 0.002 & 100 & 3.51 & 0.002 & 27.2 & 3.24 & 0.009 & - & 3.32 & 0.007 & 100 & 3.51 & 0.004 & 0.002 & 46.6 \\
\hline
\end{tabular}




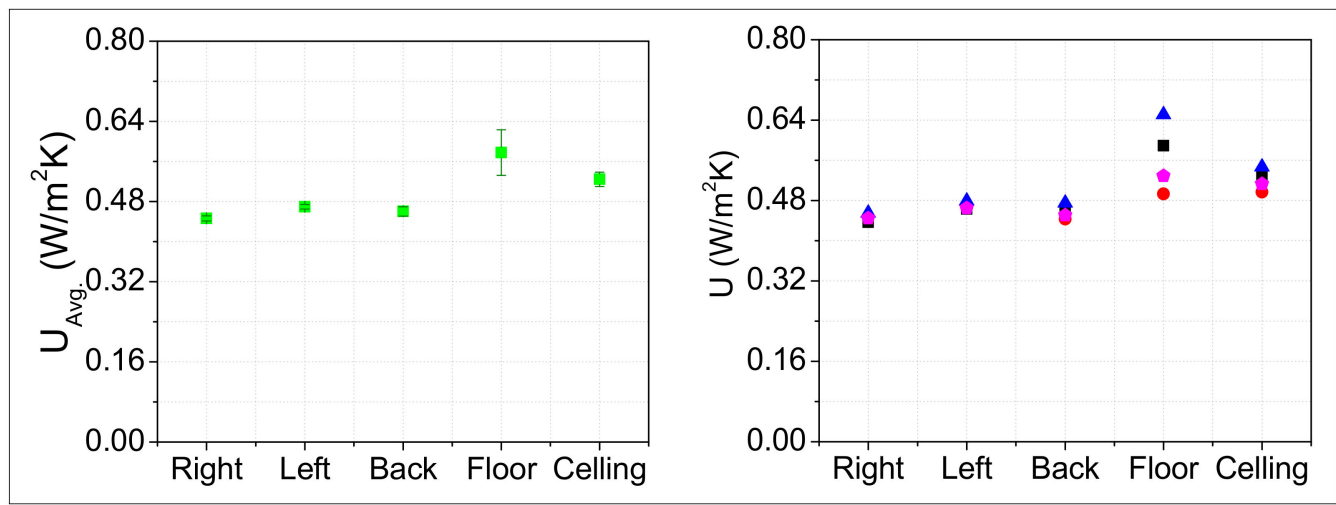

(a)
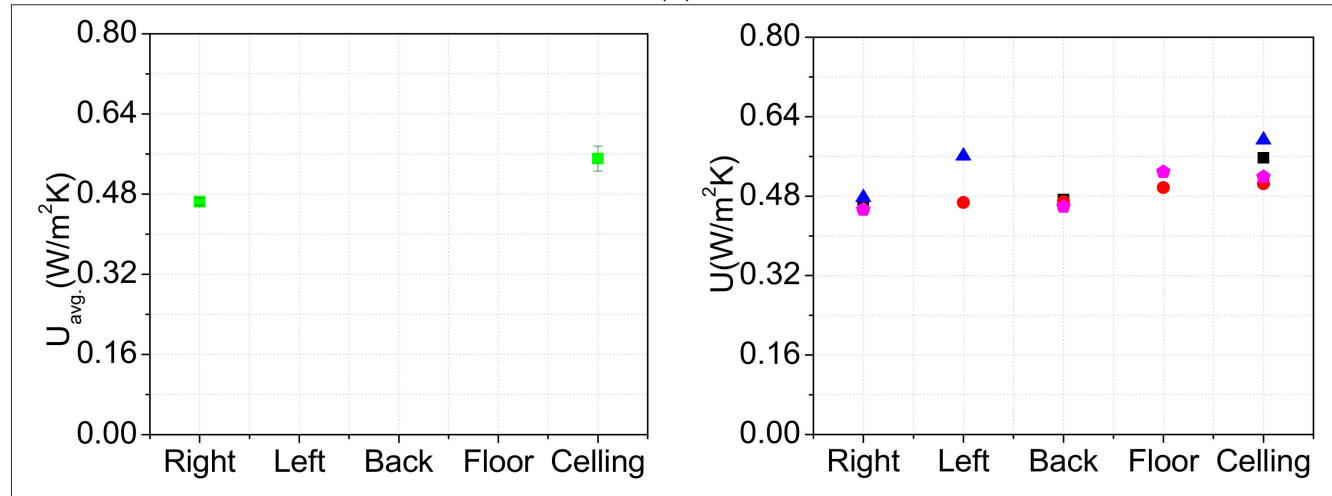

(b)
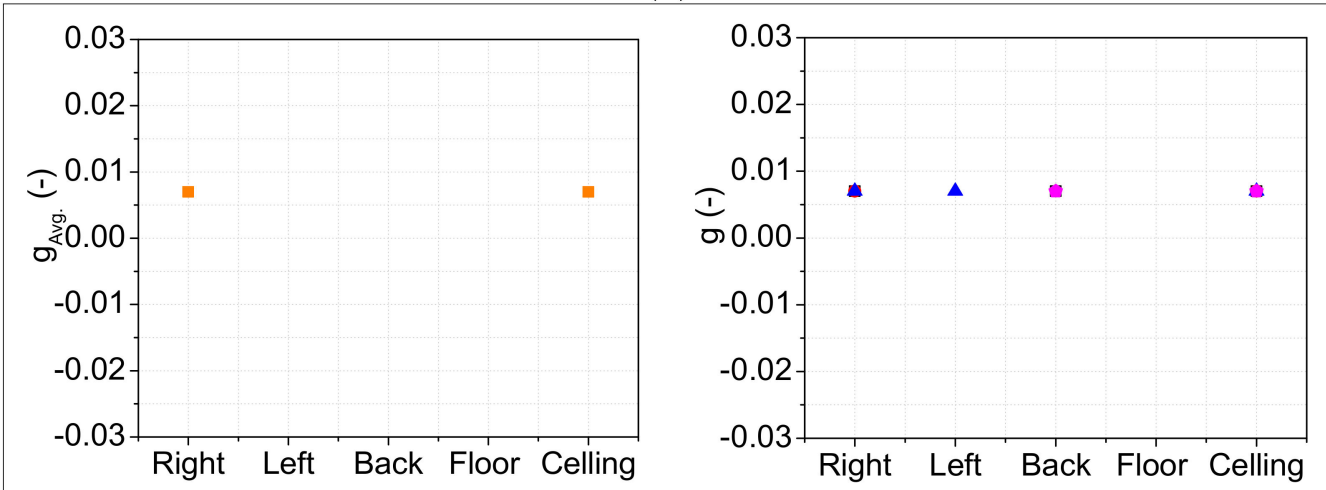

(c)

Figure 5. All the opaque walls: results obtained using a four nodes model. Left: average of $U$ value for series $\mathrm{a}, \mathrm{b}$ and c. Right: values for series a in black, series b in red, series $\mathrm{c}$ in blue and pink for the full data series d. (a) Not including solar radiation. Output: $T_{i} ;(\mathbf{b})$ including solar radiation. Output: $T_{i}$; (c) including solar radiation. Output: $T_{i}$.

The average of the residuals for these opaque elements shows the best behavior for the series $b$ (Figure $6 b, d, f)$, which is the series with the largest indoor to outdoor air temperature difference. This issue corroborates the usefulness of maximizing this driving variable introduced in Section 2.1.3. 
Table 6. Opaque walls. $\mathrm{U}$ value. Summary of the results using models that do not include solar radiation. Output: $T_{i}$. Where $e_{\mathrm{g}}$ is the error and $\mathrm{R}$ is the average of the residuals given by LORD for each data series.

\begin{tabular}{|c|c|c|c|c|c|c|c|c|c|c|c|c|c|c|c|}
\hline \multirow[b]{2}{*}{ Wall } & \multicolumn{3}{|c|}{$\rightarrow-$ Series a } & \multicolumn{3}{|c|}{- Series b } & \multicolumn{3}{|c|}{$\triangle$-Series c } & \multicolumn{3}{|c|}{- Series d } & \multicolumn{3}{|c|}{ Series $a, b, c$} \\
\hline & $\begin{array}{c}U \\
\left(W / m^{2} K\right)\end{array}$ & $\begin{array}{l}e_{U} \\
(\%)\end{array}$ & $\begin{array}{c}\mathbf{R} \\
(\mathrm{K})\end{array}$ & $\underset{\left(W / m^{2} K\right)}{U}$ & $\begin{array}{c}e_{U} \\
(\%)\end{array}$ & $\begin{array}{c}R \\
(\mathrm{~K})\end{array}$ & $\underset{\left(W / m^{2} K\right)}{U}$ & $\begin{array}{c}e_{U} \\
(\%)\end{array}$ & $\begin{array}{c}\mathrm{R} \\
(\mathrm{K})\end{array}$ & $\underset{\left(W / m^{2} K\right)}{U}$ & $\begin{array}{l}e_{U} \\
(\%)\end{array}$ & $\begin{array}{c}\mathbf{R} \\
(\mathrm{K})\end{array}$ & $\begin{array}{c}U_{\text {avg }} \\
\left(W / m^{2} K\right)\end{array}$ & $\begin{array}{c}\sigma_{U} \\
\left(W / m^{2} K\right)\end{array}$ & $\begin{array}{l}\sigma_{U} \\
(\%)\end{array}$ \\
\hline Right & 0.44 & 0.5 & 1.53 & 0.45 & 9.5 & 0.88 & 0.46 & 2.6 & 1.36 & 0.45 & 0.1 & 1.71 & 0.45 & 0.01 & 1.2 \\
\hline Left & 0.46 & 15 & 1.35 & 0.47 & 77.3 & 0.78 & 0.48 & 22.4 & 1.08 & 0.47 & 4.4 & 1.48 & 0.47 & 0.01 & 1.0 \\
\hline Back & 0.46 & - & 0.45 & 0.44 & 0.005 & 0.43 & 0.48 & 0.005 & 0.51 & 0.45 & - & 0.68 & 0.46 & 0.01 & 2.0 \\
\hline Floor & 0.59 & 4 & 2.10 & 0.49 & 50.9 & 0.83 & 0.65 & 64.3 & 1.31 & 0.53 & 5.8 & 3.22 & 0.58 & 0.05 & 7.9 \\
\hline Celling & 0.53 & 0.3 & 0.52 & 0.50 & 0.1 & 0.45 & 0.55 & 1.8 & 0.56 & 0.51 & - & 0.81 & 0.52 & 0.01 & 2.8 \\
\hline
\end{tabular}

Table 7. Opaque walls. U value. Summary of the results using models that include solar radiation. Output: $T_{i}$. Where $\mathrm{e}_{\mathrm{g}}$ is the error and $\mathrm{R}$ is the average of the residuals given by LORD for each data series.

\begin{tabular}{|c|c|c|c|c|c|c|c|c|c|c|c|c|c|c|c|}
\hline \multirow[b]{2}{*}{ Wall } & \multicolumn{3}{|c|}{$\rightarrow-$ Series a } & \multicolumn{3}{|c|}{- -Series b } & \multicolumn{3}{|c|}{$\triangle$-Series c } & \multicolumn{3}{|c|}{ - Series d } & \multicolumn{3}{|c|}{ Series $a, b, c$} \\
\hline & $\underset{\left(W / m^{2} K\right)}{U}$ & $\begin{array}{c}e_{U} \\
(\%)\end{array}$ & $\begin{array}{c}\mathrm{R} \\
(\mathrm{K})\end{array}$ & $\underset{\left(W / m^{2} K\right)}{U}$ & $\begin{array}{l}e_{U} \\
(\%)\end{array}$ & $\begin{array}{c}\mathrm{R} \\
(\mathrm{K})\end{array}$ & $\underset{\left(W / m^{2} K\right)}{U}$ & $\begin{array}{l}e_{U} \\
(\%)\end{array}$ & $\begin{array}{c}\mathrm{R} \\
\mathbf{( K )}\end{array}$ & $\underset{\left(W / m^{2} K\right)}{U}$ & $\begin{array}{l}e_{U} \\
(\%)\end{array}$ & $\begin{array}{c}\mathrm{R} \\
\mathbf{( K )}\end{array}$ & $\begin{array}{c}U_{\text {avg }} \\
\left(W / m^{2} K\right)\end{array}$ & $\begin{array}{c}\sigma_{U} \\
\left(W / m^{2} K\right)\end{array}$ & $\begin{array}{l}\sigma_{U} \\
(\%)\end{array}$ \\
\hline Right & 0.47 & 3.9 & 1.58 & 0.45 & 44.9 & 0.89 & 0.48 & 5.8 & 1.38 & 0.45 & 0.3 & 1.80 & 0.47 & 0.01 & 1.5 \\
\hline Left & 5.46 & 89.8 & 4.57 & 0.47 & 40 & 0.78 & 0.56 & 41.4 & 1.03 & 2.95 & 2.4 & 7.18 & 2.16 & 1.44 & 66.6 \\
\hline Back & 0.47 & 0.8 & 0.48 & 0.47 & 0.1 & 0.40 & 2.07 & 11.6 & 1.40 & 0.46 & 0.005 & 0.76 & 1.01 & 0.46 & 46.1 \\
\hline Floor & 8.18 & 13 & 4.58 & 0.50 & 59.4 & 0.84 & 14.38 & 7.3 & 1.99 & 0.53 & 100 & 3.26 & 7.68 & 4.01 & 52.2 \\
\hline Celling & 0.56 & 0.3 & 0.64 & 0.51 & 0.1 & 0.53 & 0.59 & 0.2 & 0.67 & 0.52 & 0.005 & 0.99 & 0.55 & 0.03 & 4.6 \\
\hline
\end{tabular}

Table 8. Opaque walls. g value. Summary of the results using models that include solar radiation. Output: $T_{i}$. Where $\mathrm{e}_{\mathrm{g}}$ is the error and $\mathrm{R}$ is the average of the residuals given by LORD for each data series.

\begin{tabular}{|c|c|c|c|c|c|c|c|c|c|c|c|c|c|c|c|}
\hline \multirow[b]{2}{*}{ Wall } & \multicolumn{3}{|c|}{$\rightarrow-$ Series a } & \multicolumn{3}{|c|}{- Series b } & \multicolumn{3}{|c|}{- -Series c } & \multicolumn{3}{|c|}{- Series d } & \multicolumn{3}{|c|}{ Series $a, b, c$} \\
\hline & $\underset{(-)}{g}$ & $\begin{array}{l}\mathrm{U}_{\mathrm{g}} \\
(\%)\end{array}$ & $\begin{array}{c}\mathrm{R} \\
(\mathrm{K})\end{array}$ & $\underset{(-)}{g}$ & $\begin{array}{l}\mathrm{Ug}_{\mathrm{g}} \\
(\%)\end{array}$ & $\begin{array}{c}\mathrm{R} \\
(\mathrm{K})\end{array}$ & $\underset{(-)}{g}$ & $\begin{array}{l}\mathrm{Ug}_{\mathrm{g}} \\
(\%)\end{array}$ & $\begin{array}{c}\mathrm{R} \\
\mathbf{( K )}\end{array}$ & $\underset{(-)}{g}$ & $\begin{array}{l}\mathrm{U}_{\mathrm{g}} \\
(\%)\end{array}$ & $\begin{array}{c}\mathrm{R} \\
(\mathrm{K})\end{array}$ & $\underset{(-)}{\text { gavg }_{(-)}}$ & $\begin{array}{l}U_{g} \\
(-)\end{array}$ & $\begin{array}{c}\mathrm{Ug}_{\mathrm{g}} \\
(\%)\end{array}$ \\
\hline Left & 0.337 & 86.3 & 4.57 & - & - & 0.78 & 0.007 & 1.3 & 1.03 & 0.263 & 2.7 & 7.18 & 0.172 & 0.095 & 55.4 \\
\hline Back & 0.007 & 0.005 & 0.48 & 0.031 & 0.005 & 0.40 & 0.911 & 14.7 & 1.40 & 0.007 & 0.005 & 0.76 & 0.316 & 0.261 & 82.5 \\
\hline Floor & 0.507 & 15.5 & 4.58 & - & - & 0.84 & 0.813 & 6.9 & 1.99 & - & - & 3.26 & 0.66 & 0.088 & 13.4 \\
\hline
\end{tabular}




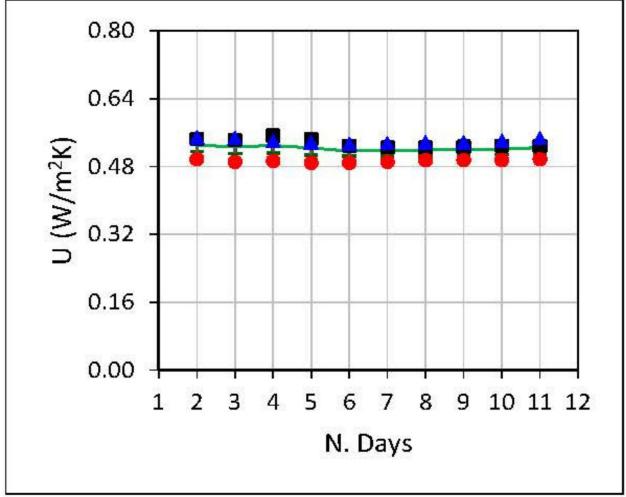

(a)

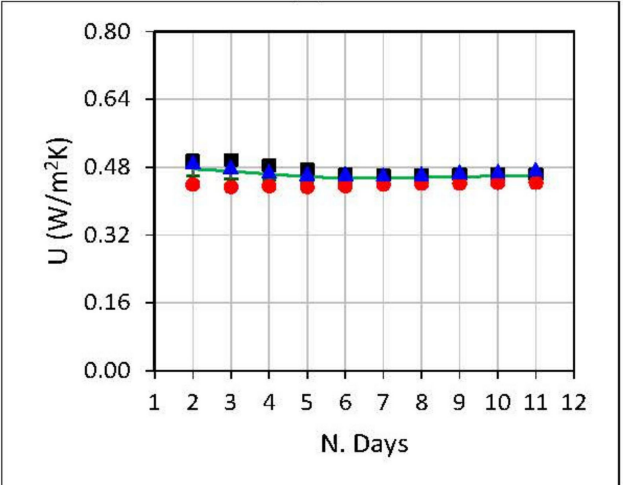

(c)

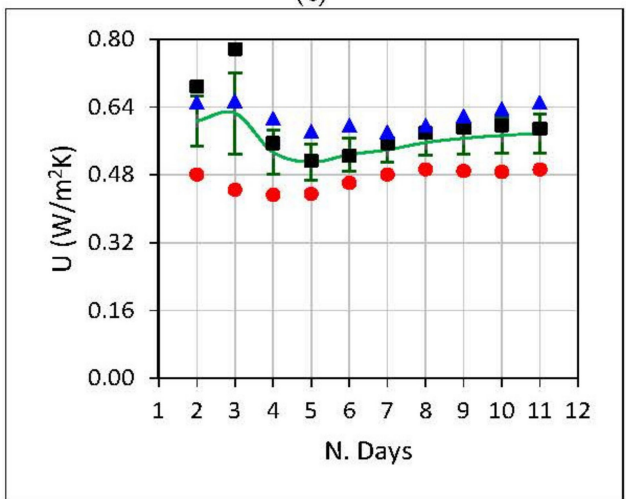

(e)

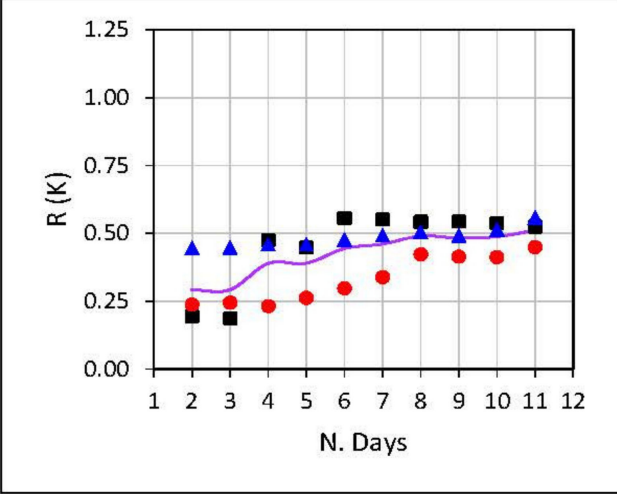

(b)

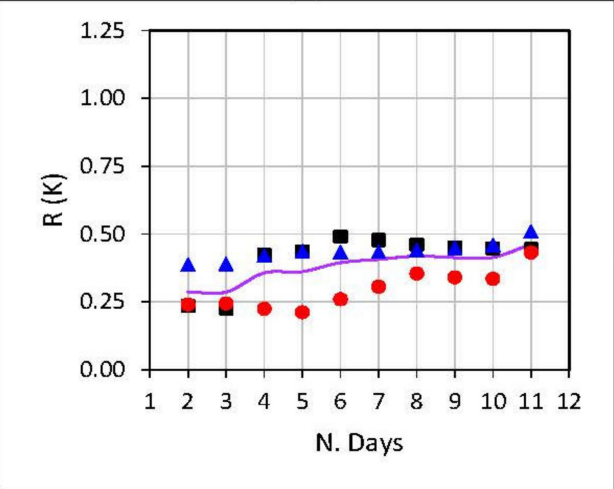

(d)

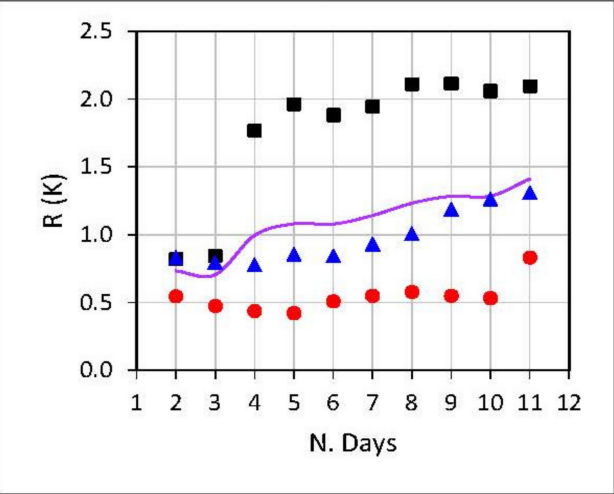

(f)

Figure 6. Opaque elements. Analysis of model performance for different length of test period. Series a in black, series $b$ in red and series $c$ in blue. The continuous lines represent the averages values from the results of the three data series $a, b$ and c. Left $U$ value. Right average of the residuals; $(\mathbf{a}, \mathbf{b})$ Ceiling; (c,d) Back wall; (e,f) Floor.

Considering the floor, the spread of the results for the different data series is relatively large for test periods shorter than seven days and increases slightly for larger test periods (Figure 6e). The average of the residuals shows different behavior for the different data series, being relatively high for series a and lower for series b and c (Figure 6f). The results for series a and $\mathrm{c}$ are far from the target theoretical values. However, the results obtained using series $b$ present better agreement with these theoretical values. The observed behavior could be explained by the effect of the perturbation caused by the solar radiation through the windows incident on the floor. The relative weight of this perturbation is smaller for series $b$ that presents the larger amplitude of indoor to outdoor air temperature difference which is the main driven variable used to obtain the $U$ value. This issue leads us to obtain better results from series $b$ even in the presence of the perturbation caused by the solar radiation incident on the interior surface of the floor. 
Table 9. Ceiling. Comparison of the results for different test lengths. $\mathrm{U}$ using the 4 nodes model without solar radiation and $T_{i}$ as output.

\begin{tabular}{|c|c|c|c|c|c|c|c|c|c|c|c|c|}
\hline \multirow[b]{2}{*}{ Days } & \multicolumn{3}{|c|}{$\rightarrow-$ Series a } & \multicolumn{3}{|c|}{- Series b } & \multicolumn{3}{|c|}{- -Series c } & \multicolumn{3}{|c|}{ Series $a, b, c$} \\
\hline & $\begin{array}{c}\mathrm{U} \\
\left(\mathrm{W} / \mathrm{m}^{2} \mathrm{~K}\right)\end{array}$ & $\begin{array}{c}e_{U} \\
(\%)\end{array}$ & $\begin{array}{c}\mathrm{R} \\
(\mathrm{K})\end{array}$ & $\begin{array}{c}U \\
\left(W / m^{2} K\right)\end{array}$ & $\begin{array}{c}e_{U} \\
(\%)\end{array}$ & $\begin{array}{c}\mathrm{R} \\
(\mathrm{K})\end{array}$ & $\underset{\left(W / m^{2} K\right)}{U}$ & $\begin{array}{c}e_{U} \\
(\%)\end{array}$ & $\begin{array}{c}\mathrm{R} \\
(\mathrm{K})\end{array}$ & $\begin{array}{c}U_{\mathrm{avg}} \\
\left(\mathrm{W} / \mathrm{m}^{2} \mathrm{~K}\right)\end{array}$ & $\begin{array}{c}\sigma_{U} \\
\left(W / m^{2} K\right)\end{array}$ & $\begin{array}{l}\sigma_{U} \\
(\%)\end{array}$ \\
\hline 2 & 0.545 & 6.3 & 0.2 & 0.497 & 7.5 & 0.2 & 0.549 & 1.7 & 0.4 & 0.530 & 0.015 & 2.8 \\
\hline 3 & 0.543 & 97.6 & 0.2 & 0.491 & 0.1 & 0.2 & 0.547 & 0.4 & 0.4 & 0.527 & 0.016 & 3.1 \\
\hline 4 & 0.553 & 0.2 & 0.5 & 0.493 & 0.1 & 0.2 & 0.541 & 0.2 & 0.5 & 0.529 & 0.017 & 3.3 \\
\hline 5 & 0.545 & 2.5 & 0.4 & 0.489 & 0.4 & 0.3 & 0.537 & 0.2 & 0.5 & 0.524 & 0.016 & 3.1 \\
\hline 6 & 0.529 & 100 & 0.6 & 0.489 & 0.0 & 0.3 & 0.533 & 0.2 & 0.5 & 0.517 & 0.013 & 2.5 \\
\hline 7 & 0.525 & 0.1 & 0.6 & 0.491 & 0.0 & 0.3 & 0.535 & 0.1 & 0.5 & 0.517 & 0.013 & 2.5 \\
\hline 8 & 0.525 & 0.8 & 0.5 & 0.495 & 0.1 & 0.4 & 0.537 & 0.3 & 0.5 & 0.519 & 0.012 & 2.3 \\
\hline 9 & 0.527 & - & 0.5 & 0.495 & 0.3 & 0.4 & 0.537 & 0.2 & 0.5 & 0.520 & 0.012 & 2.3 \\
\hline 10 & 0.529 & 0.2 & 0.5 & 0.495 & 0.0 & 0.4 & 0.541 & 0.1 & 0.5 & 0.522 & 0.013 & 2.6 \\
\hline 11 & 0.529 & - & 0.5 & 0.497 & 0.0 & 0.4 & 0.547 & 0.1 & 0.6 & 0.524 & 0.014 & 2.8 \\
\hline
\end{tabular}




\subsection{The Whole Building}

The results obtained using the different candidate models considered to obtain UA and gA values and also the validity of these results is presented and discussed in Sections 3.2.1-3.2.3. The number of nodes in the opaque branch ( 3 to 7 ) is used to identify the models hereafter.

\subsubsection{Models Considering Different Number of Nodes for the Branch Representing the Opaque Walls}

The results obtained using different number of nodes for the branch representing the opaque walls and setting the outdoor air temperature and the heating power as alternative outputs are summarized in Figure 7, and Tables 10 and 11. These tables and figure show that:

- Attending to the spread in the results obtained using the different data series, the three nodes model with $T_{i}$ as output shows the best performance.

- Attending to the residual obtained using the different data series, scarce differences are observed for the different candidate models.
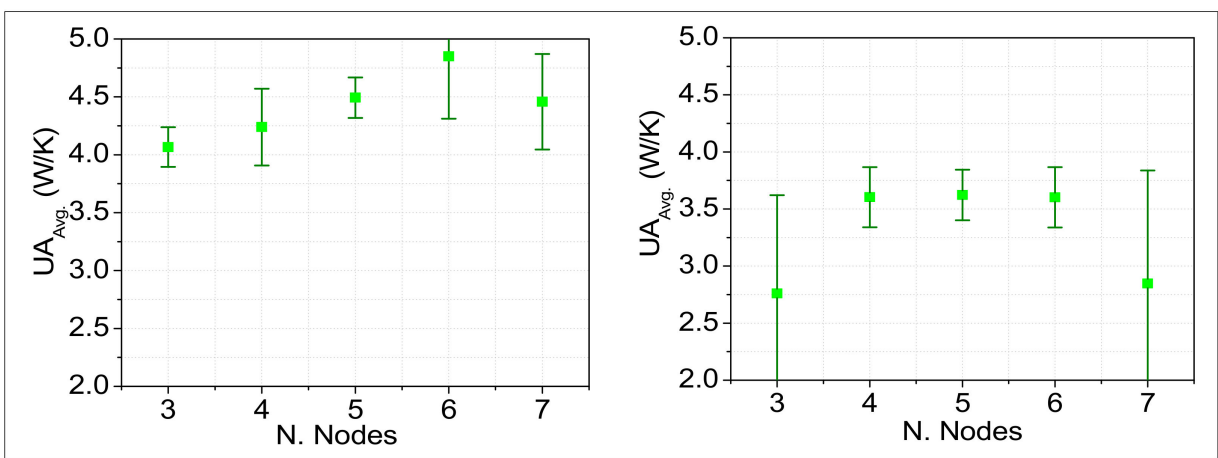

(a)
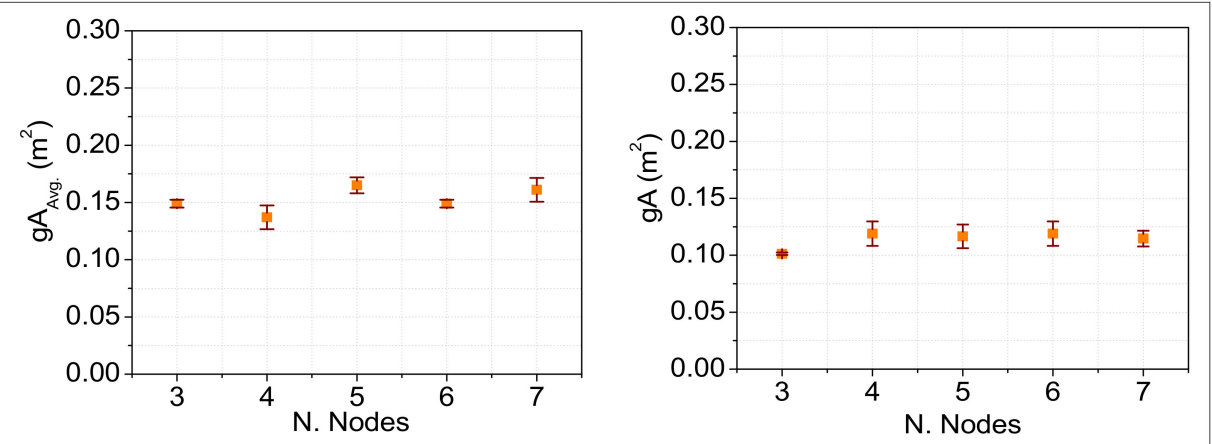

(b)
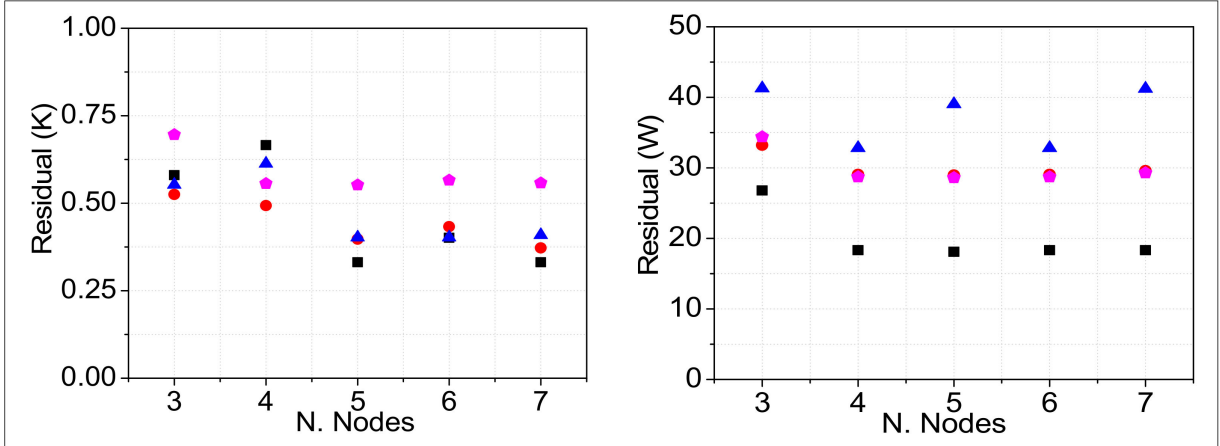

(c)

Figure 7. Whole building: results obtained using different candidate models. Left: using $T_{i}$ as output variable. Right: using $P_{\text {heating }}$ as output variable. (a) Average of UA for series a, b and c. (b) Average of gA for series a, b and c. (c) Residuals for series a, b, c and d. Series a in black, series b in red, series c in blue and pink for the full data series $d$. 
Table 10. Whole building. Summary of results. Output: $T_{i}$. UA values, and average of the residuals. Where eUA is the error and $\mathrm{R}$ is the average of the residuals given by LORD for each data series.

\begin{tabular}{|c|c|c|c|c|c|c|c|c|c|c|c|c|c|c|c|}
\hline & \multicolumn{3}{|c|}{$\rightarrow-$ Series a } & \multicolumn{3}{|c|}{- Series b } & \multicolumn{3}{|c|}{- -Series c } & \multicolumn{3}{|c|}{- Series d } & \multicolumn{3}{|c|}{ Series $a, b, c$} \\
\hline $\begin{array}{c}\mathrm{N}^{\mathrm{er}} \\
\text { Nodes }\end{array}$ & $\underset{\text { (W/K) }}{\text { UA }}$ & $\begin{array}{l}\text { eUA } \\
(\%)\end{array}$ & $\begin{array}{c}R \\
(\mathrm{~K})\end{array}$ & $\begin{array}{c}\text { UA } \\
\text { (W/K) }\end{array}$ & $\begin{array}{l}\text { eUA } \\
(\%)\end{array}$ & $\begin{array}{c}R \\
(\mathrm{~K})\end{array}$ & $\begin{array}{c}\text { UA } \\
\text { (W/K) }\end{array}$ & $\begin{array}{l}\text { eUA } \\
(\%)\end{array}$ & $\begin{array}{c}R \\
(\mathrm{~K})\end{array}$ & $\underset{\text { (W/K) }}{\text { UA }}$ & $\begin{array}{l}\text { eUA } \\
(\%)\end{array}$ & $\begin{array}{c}\mathrm{R} \\
(\mathrm{K})\end{array}$ & $\begin{array}{l}\text { UA }_{\text {avg }} \\
\text { (W/K) }\end{array}$ & $\begin{array}{c}\sigma_{\mathrm{UA}} \\
(\mathrm{W} / \mathrm{K})\end{array}$ & $\begin{array}{l}\sigma_{\text {UA }} \\
(\%)\end{array}$ \\
\hline 3 & 4.10 & 6.4 & 0.58 & 4.35 & 3.3 & 0.53 & 3.75 & 2.1 & 0.55 & 4.14 & 1.4 & 0.70 & 4.07 & 0.17 & 4.2 \\
\hline 4 & 3.68 & 2.6 & 0.67 & 4.20 & 4 & 0.49 & 4.83 & 7.4 & 0.61 & 4.15 & 0.8 & 0.56 & 4.24 & 0.33 & 7.8 \\
\hline 5 & 4.22 & 1 & 0.33 & 4.82 & - & 0.40 & 4.44 & 0.2 & 0.40 & 4.15 & 0.1 & 0.55 & 4.49 & 0.17 & 3.9 \\
\hline 6 & 4.13 & 4.8 & 0.40 & 5.99 & 14.4 & 0.43 & 4.44 & 0.5 & 0.40 & 4.05 & 2.1 & 0.57 & 4.85 & 0.54 & 11.1 \\
\hline 7 & 4.22 & 0.5 & 0.33 & 5.29 & 0.6 & 0.37 & 3.87 & 0.1 & 0.41 & 4.15 & 0.1 & 0.56 & 4.46 & 0.41 & 9.2 \\
\hline
\end{tabular}

Table 11. Whole building. Summary of results. Output: $T_{i}$. gA values, and average of the residuals. Where $\mathbf{e}_{\mathbf{g A}}$ is the error and $\mathrm{R}$ is the average of the residuals given by LORD for each data series.

\begin{tabular}{|c|c|c|c|c|c|c|c|c|c|c|c|c|c|c|c|}
\hline \multirow[b]{2}{*}{$\begin{array}{c}\mathrm{N}^{\mathrm{er}} \\
\text { Nodes }\end{array}$} & \multicolumn{3}{|c|}{$\rightarrow-$ Series a } & \multicolumn{3}{|c|}{- Series b } & \multicolumn{3}{|c|}{$\triangle$-Series c } & \multicolumn{3}{|c|}{- Series d } & \multicolumn{3}{|c|}{ Series $a, b, c$} \\
\hline & $\underset{\left(\mathrm{m}^{2}\right)}{\mathrm{gA}}$ & $\begin{array}{l}\mathbf{e}_{\mathrm{gA}} \\
(\%)\end{array}$ & $\begin{array}{c}R \\
(\mathrm{~K})\end{array}$ & $\underset{\left(\mathrm{m}^{2}\right)}{\mathrm{gA}}$ & $\begin{array}{l}\mathbf{e}_{\mathrm{gA}} \\
(\%)\end{array}$ & $\begin{array}{c}R \\
(\mathrm{~K})\end{array}$ & $\underset{\left(\mathrm{m}^{2}\right)}{\mathrm{gA}}$ & $\begin{array}{l}e_{g A} \\
(\%)\end{array}$ & $\begin{array}{c}R \\
(\mathrm{~K})\end{array}$ & $\underset{\left(\mathrm{m}^{2}\right)}{\mathrm{gA}}$ & $\begin{array}{l}\mathbf{e}_{\mathrm{gA}} \\
(\%)\end{array}$ & $\begin{array}{c}R \\
\text { (K) }\end{array}$ & $\begin{array}{c}\mathbf{g A}_{\text {avg }} \\
\left(\mathrm{m}^{2}\right)\end{array}$ & $\begin{array}{l}\sigma_{\mathrm{gA}} \\
\left(\mathrm{m}^{2}\right)\end{array}$ & $\begin{array}{l}\sigma_{\mathrm{gA}} \\
(\%)\end{array}$ \\
\hline 3 & 0.153 & 0.1 & 0.58 & 0.153 & 10.6 & 0.53 & 0.141 & 2.7 & 0.55 & 0.153 & 1.6 & 0.70 & 0.149 & 0.003 & 2.3 \\
\hline 4 & 0.117 & 5.3 & 0.67 & 0.153 & 2.8 & 0.49 & 0.141 & 3.1 & 0.61 & 0.165 & 5.4 & 0.56 & 0.137 & 0.01 & 7.6 \\
\hline 5 & 0.165 & 0.005 & 0.33 & 0.177 & - & 0.40 & 0.153 & 0.8 & 0.40 & 0.165 & 0.2 & 0.55 & 0.165 & 0.007 & 4.2 \\
\hline 6 & 0.141 & 0.005 & 0.40 & 0.153 & 12.4 & 0.43 & 0.153 & 0.2 & 0.40 & 0.141 & 1.2 & 0.57 & 0.149 & 0.003 & 2.3 \\
\hline 7 & 0.165 & 0.005 & 0.33 & 0.177 & 0.9 & 0.37 & 0.141 & 0.8 & 0.41 & 0.165 & 0.005 & 0.56 & 0.161 & 0.01 & 6.5 \\
\hline
\end{tabular}


Taking into account the observed performance of the considered models, the three nodes model, with $T_{i}$ as output, including solar radiation has been chosen to give the final results for the UA and gA values. This model is named as Model 0 hereafter.

Focusing on the results obtained from the different data series, the results obtained from series $a$ is the one that shows the best agreement with the theoretical values and with the results obtained applying a different analysis approach (see Tables 1, 10 and 11). This is logical taking into account that the test conditions from this data series was optimized for the application of system identifications techniques, as explained in the Section 2.1.3.

\subsubsection{Model Performance for Different Length of the Test Period}

The results of the analysis carried out are summarized in Figure 8, and Tables 12 and 13. These tables and figure show that the spreads in the UA and gA obtained for the different data series is relatively high for the shortest lengths of test periods. These spreads oscillate for the different lengths of test period with a decreasing tendency for increasing lengths of the test period and is significantly small for a test period of four days in the case of UA. It is also relatively low for lengths of the test periods of five and eight days (Figure 8a). However, the gA value shows large spread for test periods shorter than six days and is relatively low for tests periods of six and eight days (Figure $8 \mathrm{~b}$ ). The average of the residuals does not show relevant differences for the different lengths of test period. These residuals are low and in a range that is similar to the range of the uncertainty of the measurement of the output variable.

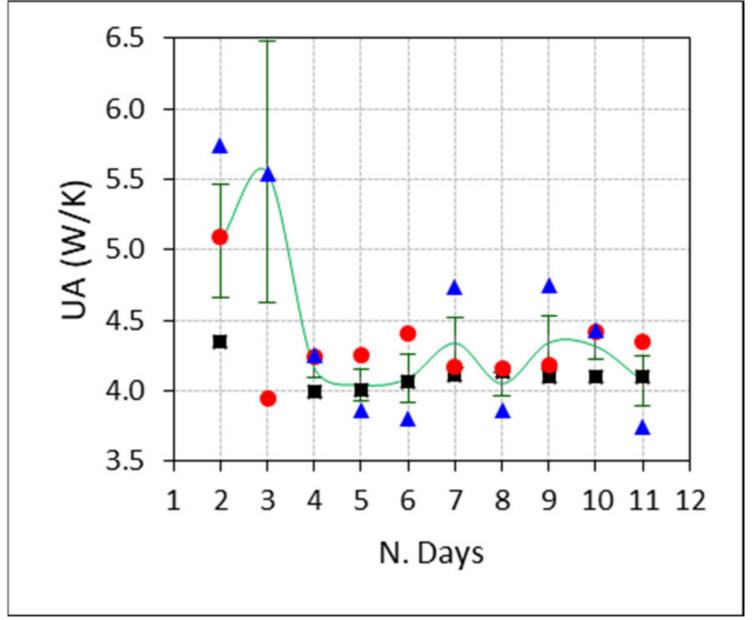

(a)

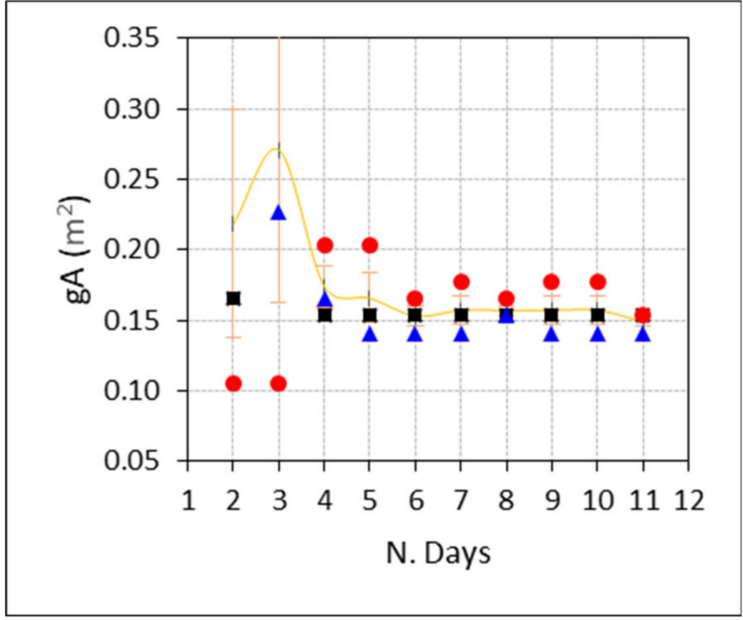

(b)

Figure 8. Whole building. Analysis of model performance for different length of test period. Series a in black, series $b$ in red and series $c$ in blue. The continuous lines represent the average values from the results of the three data series a, b and c. (a) UA value. (b) gA value. 
Table 12. Whole building. Comparison of the results for different test lengths. UA for the 3 nodes model with solar radiation and $T_{i}$ as output.

\begin{tabular}{|c|c|c|c|c|c|c|c|c|c|c|c|c|}
\hline \multirow[b]{2}{*}{ Days } & \multicolumn{3}{|c|}{$\rightarrow-$ Series a } & \multicolumn{3}{|c|}{ - Series b } & \multicolumn{3}{|c|}{- -Series c } & \multicolumn{3}{|c|}{ Series $a, b, c$} \\
\hline & $\begin{array}{c}\text { UA } \\
\text { (W/K) }\end{array}$ & $\begin{array}{l}e_{\text {UA }} \\
(\%)\end{array}$ & $\begin{array}{c}R \\
(\mathrm{~K})\end{array}$ & $\begin{array}{c}\text { UA } \\
(W / K)\end{array}$ & $\begin{array}{l}e_{\text {UA }} \\
(\%)\end{array}$ & $\begin{array}{c}R \\
(\mathrm{~K})\end{array}$ & $\begin{array}{c}\text { UA } \\
\text { (W/K) }\end{array}$ & $\begin{array}{l}\text { eUA } \\
(\%)\end{array}$ & $\begin{array}{c}\mathrm{R} \\
(\mathrm{K})\end{array}$ & $\begin{array}{l}\mathbf{U A}_{\text {avg }} \\
\text { (W/K) }\end{array}$ & $\begin{array}{c}\sigma_{\mathrm{UA}} \\
(\mathrm{W} / \mathrm{K})\end{array}$ & $\begin{array}{c}\sigma_{\mathrm{UA}} \\
(\%)\end{array}$ \\
\hline 2 & 4.35 & 14.3 & 0.4 & 5.09 & 18.4 & 0.6 & 5.75 & 10.9 & 0.3 & 5.06 & 0.41 & 8.0 \\
\hline 3 & 7.17 & 8.7 & 0.4 & 3.95 & 2.4 & 0.4 & 5.54 & 5.3 & 0.4 & 5.55 & 0.93 & 16.8 \\
\hline 4 & 4.00 & 11 & 0.6 & 4.24 & 0.5 & 0.4 & 4.25 & 4 & 0.5 & 4.16 & 0.07 & 1.7 \\
\hline 5 & 4.01 & 3.7 & 0.6 & 4.25 & 1.1 & 0.4 & 3.87 & 12 & 0.5 & 4.04 & 0.11 & 2.7 \\
\hline 6 & 4.06 & 8 & 0.6 & 4.41 & 7.4 & 0.4 & 3.80 & 2.9 & 0.6 & 4.09 & 0.18 & 4.3 \\
\hline 7 & 4.11 & 2.8 & 0.6 & 4.17 & 0.2 & 0.4 & 4.73 & 7.2 & 0.6 & 4.18 & 0.31 & 7.5 \\
\hline 8 & 4.13 & 7.8 & 0.6 & 4.16 & 0.4 & 0.4 & 3.87 & 4.8 & 0.6 & 4.05 & 0.08 & 2.1 \\
\hline 9 & 4.10 & 1.6 & 0.6 & 4.18 & 2.3 & 0.4 & 4.74 & 5.8 & 0.6 & 4.34 & 0.19 & 4.3 \\
\hline 10 & 4.10 & 2.2 & 0.6 & 4.42 & 5 & 0.4 & 4.43 & 10.3 & 0.6 & 4.31 & 0.10 & 2.2 \\
\hline 11 & 4.10 & 6.8 & 0.6 & 4.35 & 1.7 & 0.5 & 3.75 & 2.9 & 0.6 & 4.07 & 0.17 & 4.3 \\
\hline
\end{tabular}

Table 13. Whole building. Comparison of the results for different test lengths. gA using the 3 nodes model with solar radiation and $T_{i}$ as output.

\begin{tabular}{|c|c|c|c|c|c|c|c|c|c|c|c|c|}
\hline \multirow[b]{2}{*}{ Days } & \multicolumn{3}{|c|}{$\rightarrow$-Series a } & \multicolumn{3}{|c|}{- Series b } & \multicolumn{3}{|c|}{- -Series c } & \multicolumn{3}{|c|}{ Series $a, b, c$} \\
\hline & $\underset{\left(\mathrm{m}^{2}\right)}{\mathrm{gA}}$ & $\begin{array}{l}\mathbf{e}_{\mathrm{gA}} \\
(\%)\end{array}$ & $\begin{array}{c}\mathrm{R} \\
\text { (K) }\end{array}$ & $\underset{\left(\mathrm{m}^{2}\right)}{\mathrm{gA}}$ & $\begin{array}{l}\mathbf{e}_{\mathrm{gA}} \\
(\%)\end{array}$ & $\begin{array}{c}\mathrm{R} \\
(\mathrm{K})\end{array}$ & $\underset{\left(\mathrm{m}^{2}\right)}{\mathrm{gA}}$ & $\begin{array}{l}\mathbf{e}_{\mathrm{gA}} \\
(\%)\end{array}$ & $\begin{array}{c}\mathrm{R} \\
\text { (K) }\end{array}$ & $\begin{array}{c}\mathbf{g A}_{\text {avg }} \\
\left(\mathbf{m}^{2}\right)\end{array}$ & $\begin{array}{l}\sigma_{\mathrm{gA}} \\
\left(\mathrm{m}^{2}\right)\end{array}$ & $\begin{array}{l}\sigma_{\mathrm{gA}} \\
(\%)\end{array}$ \\
\hline 2 & 0.165 & 2.2 & 0.4 & 0.105 & 100.0 & 0.6 & 0.385 & 1.0 & 0.3 & 0.218 & 0.081 & 37.0 \\
\hline 3 & 0.481 & 2.8 & 0.4 & 0.105 & 15.5 & 0.4 & 0.227 & 1.4 & 0.4 & 0.271 & 0.109 & 40.1 \\
\hline 4 & 0.153 & 3.8 & 0.6 & 0.203 & 0.8 & 0.4 & 0.165 & 2.1 & 0.5 & 0.174 & 0.014 & 8.3 \\
\hline 5 & 0.153 & 2.4 & 0.6 & 0.203 & 4.4 & 0.4 & 0.141 & 6.8 & 0.5 & 0.166 & 0.018 & 10.8 \\
\hline 6 & 0.153 & 0.9 & 0.6 & 0.165 & 27.9 & 0.4 & 0.141 & 3.6 & 0.6 & 0.153 & 0.007 & 4.5 \\
\hline 7 & 0.153 & 1.1 & 0.6 & 0.177 & 1.1 & 0.4 & 0.141 & 13.5 & 0.6 & 0.145 & 0.017 & 12.0 \\
\hline 8 & 0.153 & 4.8 & 0.6 & 0.165 & 5.1 & 0.4 & 0.153 & 0.1 & 0.6 & 0.157 & 0.003 & 2.2 \\
\hline 9 & 0.153 & 0.2 & 0.6 & 0.177 & 8.5 & 0.4 & 0.141 & 10.7 & 0.6 & 0.157 & 0.01 & 6.6 \\
\hline 10 & 0.153 & 0.1 & 0.6 & 0.177 & 8.0 & 0.4 & 0.141 & 3.8 & 0.6 & 0.157 & 0.01 & 6.6 \\
\hline 11 & 0.153 & 0.1 & 0.6 & 0.153 & 3.1 & 0.5 & 0.141 & 2.7 & 0.6 & 0.149 & 0.003 & 2.3 \\
\hline
\end{tabular}




\subsubsection{Models Including Non-Measured Variables}

The results obtained for the considered models including non-measured variables are summarized in Tables 14 and 15, and discussed in the following:

- Model 1 using a synthetic variable, instead of the measured $G_{v}$, has given good UA estimates only if the data series is long enough (series $\mathrm{d}$ ). This result indicates that this strategy is useful for a cost reduction of the test set up when the length of the test campaign is not critical.

- Model 2 using a synthetic outdoor air temperature, instead of the measured $T_{e}$, has shown a better behavior when the indoor air temperature is higher (series $a$ and $b$ ). In this case the errors due to the difference between the true $T_{e}$ and $T_{e_{-} \text {synthetic }}$ have a relative lower influence than having a lower indoor to outdoor temperature difference. This result indicates that when the test conditions allow to achieve a high enough indoor to outdoor temperature difference and the TMY of the place is available, a cost reduction of the test set up by eliminating the measurement of the outdoor air temperature is possible.

- Model 3 using a binary variable, instead of the measured $P_{\text {heating, }}$ has given good results for all the data series. These results support the validity of a model implementing a moderate cost reduction regarding the reference model 0 as discussed in Section 3.2.

- Model 4 which is model 3 modified by the parameter $\mathrm{A}_{4}$ set as an identifiable parameter instead of a fixed value, has given good UA estimates only if the data series is long enough (series d). This result indicates that this strategy is useful for a cost reduction of the test set up when the length of the test campaign is not critical.

- Model 5 using the set point indoors air temperature, instead of the measured $T_{i}$, has shown good results only when this set point is remarkably high (series b) which is useful for testing empty buildings allowing setting up a high enough $T_{i}$.

The results obtained from these alternative models which are in the range of the expected values are highlighted in green in Tables 14 and 15. 
Table 14. Whole building. Models including non-measured variables. Output: $T_{i}$. Summary of the results. UA values, and average of the residuals.

\begin{tabular}{|c|c|c|c|c|c|c|c|c|c|c|c|c|c|c|c|}
\hline \multirow[b]{2}{*}{ Model } & \multicolumn{3}{|c|}{- -Series a } & \multicolumn{3}{|c|}{- -Series b } & \multicolumn{3}{|c|}{ A-Series c } & \multicolumn{3}{|c|}{- Series d } & \multicolumn{3}{|c|}{ Series $a, b, c$} \\
\hline & $\begin{array}{c}\text { UA } \\
\text { (W/K) }\end{array}$ & $\begin{array}{l}\mathbf{e}_{\mathrm{UA}} \\
\mathbf{( \% )}\end{array}$ & $\begin{array}{c}\mathrm{R} \\
\text { (K) }\end{array}$ & $\begin{array}{c}\text { UA } \\
\text { (W/K) }\end{array}$ & $\begin{array}{c}\mathbf{e}_{\mathrm{UA}} \\
\mathbf{( \% )}\end{array}$ & $\begin{array}{c}\mathrm{R} \\
(\mathrm{K})\end{array}$ & $\begin{array}{c}\text { UA } \\
\text { (W/K) }\end{array}$ & $\begin{array}{l}\mathrm{e}_{\mathrm{UA}} \\
\mathbf{( \% )}\end{array}$ & $\begin{array}{c}\mathrm{R} \\
\text { (K) }\end{array}$ & $\begin{array}{c}\text { UA } \\
\text { (W/K) }\end{array}$ & $\begin{array}{l}\mathrm{e}_{\mathrm{UA}} \\
(\%)\end{array}$ & $\begin{array}{c}\mathrm{R} \\
\text { (K) }\end{array}$ & $\begin{array}{l}\text { UA }_{\text {avg }} \\
\text { (W/K) }\end{array}$ & $\begin{array}{c}\sigma_{\mathrm{UA}} \\
(\mathrm{W} / \mathrm{K})\end{array}$ & $\begin{array}{l}\sigma_{\mathrm{UA}} \\
(\%)\end{array}$ \\
\hline 0 & 4.10 & 6.4 & 0.6 & 4.35 & 3.3 & 0.5 & 3.75 & 2.1 & 0.6 & 4.14 & 1.4 & 0.7 & 4.07 & 0.17 & 4.2 \\
\hline 1 & 3.02 & 41.7 & 2.3 & 3.23 & 18.9 & 1.0 & 3.38 & 100 & 2.4 & 3.97 & 56 & 3.0 & 3.21 & 0.10 & 3.2 \\
\hline 2 & 4.00 & 6.4 & 0.7 & 3.88 & 4 & 0.6 & 3.58 & 11 & 1.2 & 4.00 & 33.5 & 1.9 & 3.82 & 0.12 & 3.2 \\
\hline 3 & 4.09 & 5.3 & 0.6 & 4.26 & 3.4 & 0.5 & 3.72 & 4.1 & 0.6 & 3.87 & 1.2 & 0.7 & 4.03 & 0.16 & 3.9 \\
\hline 4 & 35.45 & 2.7 & 0.6 & 2.93 & 8.1 & 0.5 & 3.22 & 3.5 & 0.6 & 3.91 & 19.2 & 0.7 & 13.87 & 9.39 & 67.7 \\
\hline $5^{1}$ & - & - & - & 4.04 & 0.1 & $31.4^{1}$ & 4.47 & 0.005 & $40.2^{1}$ & 3.89 & 0.2 & $49.0^{1}$ & - & - & - \\
\hline
\end{tabular}

Table 15. Whole building. Models including non-measured variables. Output: $T_{i}$. Summary of the results. gA values, and average of the residuals.

\begin{tabular}{|c|c|c|c|c|c|c|c|c|c|c|c|c|c|c|c|}
\hline \multirow[b]{2}{*}{ Model } & \multicolumn{3}{|c|}{$\rightarrow-$ Series a } & \multicolumn{3}{|c|}{- -Series b } & \multicolumn{3}{|c|}{$\triangle-$ Series c } & \multicolumn{3}{|c|}{- Series d } & \multicolumn{3}{|c|}{ Series $a, b, c$} \\
\hline & $\underset{\left(\mathbf{m}^{2}\right)}{\mathrm{gA}}$ & $\begin{array}{l}e_{g A} \\
(\%)\end{array}$ & $\begin{array}{c}\mathrm{R} \\
(\mathrm{K})\end{array}$ & $\underset{\left(\mathrm{m}^{2}\right)}{\mathrm{gA}}$ & $\begin{array}{l}\mathbf{e}_{\mathrm{gA}} \\
(\%)\end{array}$ & $\begin{array}{c}\mathrm{R} \\
(\mathrm{K})\end{array}$ & $\underset{\left(\mathrm{m}^{2}\right)}{\mathrm{gA}}$ & $\begin{array}{l}e_{g A} \\
(\%)\end{array}$ & $\begin{array}{c}\mathrm{R} \\
(\mathrm{K})\end{array}$ & $\underset{\left(\mathrm{m}^{2}\right)}{\mathrm{gA}}$ & $\begin{array}{l}\mathbf{e}_{\mathrm{gA}} \\
(\%)\end{array}$ & $\begin{array}{c}\mathrm{R} \\
(\mathrm{K})\end{array}$ & $\begin{array}{l}\mathbf{U A}_{\text {avg }} \\
\left(\mathrm{m}^{2}\right)\end{array}$ & $\begin{array}{c}\sigma_{\mathrm{gA}} \\
\left(\mathrm{m}^{2}\right)\end{array}$ & $\begin{array}{l}\sigma_{\mathrm{gA}} \\
(\%)\end{array}$ \\
\hline 0 & 0.153 & 0.1 & 0.6 & 0.153 & 10.6 & 0.5 & 0.141 & 2.7 & 0.6 & 0.153 & 1.6 & 0.7 & 0.149 & 0.003 & 2.3 \\
\hline 1 & - & - & - & - & - & - & - & - & - & - & - & - & - & - & - \\
\hline 2 & 0.165 & 0.6 & 0.7 & 0.141 & 8.3 & 0.6 & 0.227 & 1.4 & 1.2 & 0.177 & 32.3 & 1.9 & 0.178 & 0.025 & 14.0 \\
\hline 3 & 0.153 & 4.6 & 0.6 & 0.153 & 2.4 & 0.5 & 0.141 & 3.8 & 0.6 & 0.141 & 1.3 & 0.7 & 0.149 & 0.003 & 2.3 \\
\hline 4 & 1.361 & 0.4 & 0.6 & 0.105 & 17.4 & 0.5 & 0.105 & 0.8 & 0.6 & 0.141 & 20.4 & 0.7 & 0.524 & 0.363 & 69.2 \\
\hline $5^{1}$ & - & - & - & 0.151 & 0.2 & $31.4^{1}$ & 0.100 & 0.005 & $40.2^{1}$ & 0.100 & 0.005 & $49.0^{1}$ & - & - & - \\
\hline
\end{tabular}




\section{Conclusions}

The reported systematic analysis has demonstrated the capability of the dynamic data-based RC models to assess the $U$ value of opaque walls as well as the UA and gA values of whole buildings. The results and conclusions are supported by the richness of the data series recorded under very different conditions of the tests carried out on a benchmark set-up. Additionally, the well-known theoretical target values and the results obtained using other method give strong support to the validity of the obtained results.

The following conclusions were extracted from the one-dimensional analysis carried out to obtain the $\mathrm{U}$ value of the opaque walls, ceiling and floor:

- The best performance among all the candidate models has been observed in the four nodes model, with $T_{i}$ as output, non-including solar radiation. This model has been chosen to give the final results for the $U$ value of the opaque walls, ceiling and floor.

- The results obtained using models assigning the heat flux as output instead of the indoor air temperature did not show significant differences regarding the results obtained using the chosen model.

- The results obtained using models including the solar radiation do not show significant differences regarding the chosen model that do not include this variable. This result can be explained in two different ways, both leading to conclude that including the solar radiation on the opaque wall models is not convenient, (1) either because its effect is in practice negligible on the heat flux measured through the internal surfaces of these walls, or (2) because its effect is in the range of the uncertainty of the measurement of heat flux. In this case, modelling the effect of the solar radiation from the recorded data is not possible.

The following conclusions were extracted from the three-dimensional energy balance and analysis carried out to determine the UA and gA values of the whole building:

- Taking into account the observed performance of the considered models, the best performance among all the candidate models has been observed in the three nodes model, with $T_{i}$ as output, including the solar radiation. This model has been chosen to give the final results for the UA and gA values because it shows the best performance attending to the spread in the results obtained using different data series.

- The data series that was optimized for the application of system identifications techniques (series a including a ROLBS power sequence), gave the most accurate results, which makes sense taking into account that a system identification tool has been applied to obtain these parameters.

The analysis of the influence of the length of the test periods on the performance of the chosen models has shown that this length is relevant to the accuracy of the results. The worse performance was observed for the lowest length with improving tendencies and certain oscillation when the length is increased. This tendency is slightly seen for the $U$ value of opaque walls but is more evident for the whole building that shows very bad performance for the lowest test periods. In both cases (opaque walls and whole building) six-day and eight-day test lengths have shown the best performances. These issues evidence the usefulness of analyzing the optimum length for each case study.

The following conclusions were extracted from the three-dimensional energy balance and analysis carried out to determine the UA and gA values of the whole building using non-measured variables reducing the cost of experiment set up and simplifying it:

- If the heating power has an on/off pattern, models can give accurate results including this contribution to the energy balance as a binary variable that is one when the heating is on and zero when the heating is off, together with a constant coefficient fixed to the average of the heating power when it is on. The same model avoiding the average of the heating power when it is on can give also acceptable results for long enough testing periods. 
- Using a synthetic variable, instead of the measured $G_{v}$, can give good enough results when the tests campaign is long enough.

- Using a synthetic outdoor air temperature, instead of the measured $T_{e}$, can give acceptable results when the test conditions allow to achieve a high enough indoor to outdoor temperature difference and the TMY of the place is available.

- Using the set point indoors air temperature, instead of the measured $T_{i}$, can give good results only when this set point is remarkably high, which is useful for testing empty buildings allowing setting up a high enough indoor air temperature.

It must be highlighted that the models chosen to obtain the final result are highly dependent on the characteristics of the building envelope. The best models identified for this case study cannot be used arbitrarily to other buildings. The application of this modelling approach to any other building typology requires one to follow the same process presented in this article. First, constructing several candidate models based on physical criteria and feasible approximations. Afterwards, selecting the best model following the steps and the validation criteria presented in this paper. The identification of the most suitable model output, the optimum number of nodes to represent the opaque elements, determining if the transmission of the solar radiation through the opaque walls is or is not relevant, and the assessment of the robustness of the results, are key aspects that can show different behavior in different buildings and consequently must be analyzed in each case study.

The analysis reported in this paper added to other published works constitutes a collection of methods systematically applied and validated by means of their application to high quality benchmark data. This material provides strong background and support to the development of procedures for in-situ performance assessment of the building fabric, from data recorded by the on-board monitoring systems, from experimental campaigns conducted under a wide variety of dynamic conditions.

The presented methodology for building energy performance assessment would be very useful to carry out diagnosis, resulting in a guidance to assist energy rehabilitations, and also to assess the effectiveness of such refurbishments once implemented. A large proportion of the buildings that need an energy rehabilitation are in-use. The capability to carry out such analysis using on-board monitoring system on in-use buildings, would contribute to reduce the intrusiveness of these assessment techniques, enhancing the readiness for deployment of this methodology.

Further research work to be undertaken in this area should expand the generality of the presented approach and its validity. In order to achieve these objectives, case studies increasing gradually the level of reality should be considered. In this context, the simplified building considered in this paper, and an extended test campaign that is available, are useful to study the following relevant aspects: extend the analysis to other months (including summer, spring and autumn), and also to study the feasibility to characterize the building in the presence of air infiltrations, different building orientations and incorporating phase change materials. Additionally, other buildings should be considered as case studies, to continue expanding the generality of these methods and extending the study to different building typologies under different weather conditions.

Author Contributions: Data curation, Y.O.-G. and S.C.; Data analysis, elaboration of graphs and synthesis of results, Y.O.-G. and H.H.; writing-review and editing J.A. and J.P.X. Methodology and writing-original draft preparation, M.J.J. All authors have read and agreed to the published version of the manuscript.

Funding: This research was funded by the Spanish Ministry of Science and Technology through the In-Situ-BEPA-MAS project, reference PID2019-105046RB-I00. The authors wish to express their gratitude for these funds.

Acknowledgments: The authors thank to IEA EBC Annex 58 for giving access to the Round Robin Test Box that was used in the work reported in this paper. Y. Olazo-Gómez acknowledges the support provided by the Mexican "Consejo Nacional de Ciencia y Tecnología (CONACYT)" given through its doctoral scholarship program, that facilitated her stay at CIEMAT's Plataforma Solar de Almería in Spain.

Conflicts of Interest: The authors declare no conflict of interest. 


\section{References}

1. Tian, W.; Heo, Y.; de Wilde, P.; Li, Z.; Yan, D.; Park, C.S.; Feng, X.; Augenbroe, G. A review of uncertainty analysis in building energy assessment. Renew. Sustain. Energy Rev. 2018, 93, 285-301. [CrossRef]

2. Kampelis, N.; Gobakis, K.; Vagias, V.; Kolokotsa, D.; Standardi, L.; Isidori, D.; Cristalli, C.; Montagnino, F.M.; Paredes, F.; Muratore, P.; et al. Evaluation of the performance gap in industrial, residential \& tertiary near-Zero energy buildings. Energy Build. 2017, 148, 58-73. [CrossRef]

3. DYNASTEE Network. Available online: https://dynastee.info/ (accessed on 15 July 2020).

4. EBC Executive Committtee; International Energy Agency. Strategic Plan 2019-2024. Energy in Buildings and Communities Technology Collaboration Programme; AECOM Ltd.: Birmingham, UK, 2019.

5. Cuerda, E.; Guerra-Santin, O.; Sendra, J.J.; Neila, F.J. Understanding the performance gap in energy retrofitting: Measured input data for adjusting building simulation models. Energy Build. 2020, 209, 109688. [CrossRef]

6. Sánchez, M.N.; Soutullo, S.; Olmedo, R.; Bravo, D.; Castaño, S.; Jiménez, M.J. An experimental methodology to assess the climate impact on the energy performance of buildings: A ten-year evaluation in temperate and cold desert areas. Appl. Energy 2020, 264, 114730. [CrossRef]

7. Shirvani Dastgerdi, A.; Sargolini, M.; Broussard Allred, S.; Chatrchyan, A.; De Luca, G. Climate Change and Sustaining Heritage Resources: A Framework for Boosting Cultural and Natural Heritage Conservation in Central Italy. Climate 2020, 8, 26. [CrossRef]

8. Escandón, R.; Suárez, R.; Sendra, J.J. On the assessment of the energy performance and environmental behaviour of social housing stock for the adjustment between simulated and measured data: The case of mild winters in the Mediterranean climate of southern Europe. Energy Build. 2017, 152, 418-433. [CrossRef]

9. Porcar, B.; Soutullo, S.; Enríquez, R.; Jiménez, M.J. Quantification of the uncertainties produced in the construction process of a building through simulation tools: A case study. J. Build. Eng. 2018, 20, 377-386. [CrossRef]

10. Enríquez, R.; Jiménez, M.J.; Heras, M.R. Towards non-intrusive thermal load Monitoring of buildings: BES calibration. Appl. Energy 2017, 191, 44-54. [CrossRef]

11. Soutullo Castro, S.; Suárez López, M.J.; García Menéndez, D.; Blanco Marigorta, E. Decision matrix methodology for retrofitting techniques of existing buildings. J. Clean. Prod. 2019, 240, 118153. [CrossRef]

12. Annex 58 of the Programme "(EBC)" of the IEA on "Reliable Building Energy Performance Characterisation Based on Full Scale Dynamic Measurements". 2011-2016. Available online: http://www.iea-ebc.org/projects/ project?AnnexID=58 (accessed on 15 July 2020).

13. Annex 71 of the Programme "(EBC)" of the IEA on "EBC Annex 71. Building Energy Performance Assessment Based on In-Situ Measurements". 2016-2021. Available online: http://www.iea-ebc.org/projects/project? AnnexID=71 (accessed on 15 July 2020).

14. Marshall, A.; Fitton, R.; Swan, W.; Farmer, D.; Johnston, D.; Benjaber, M.; Ji, Y. Domestic building fabric performance: Closing the gap between the in-situ measured and modelled performance. Energy Build. 2017, 150, 307-317. [CrossRef]

15. Jiménez, M.J. IEA, EBC Annex 58, Report of Subtask 3, Part 1. Thermal Performance Characterization Based on Full Scale Testing-Description of the Common Exercises and Physical Guidelines; Jiménez, M.J., Ed.; KU Leuven: Leuven, Belgium, 2016; ISBN 9789460189876. Available online: http://www.iea-ebc.org/Data/publications/ EBC_Annex_58_Final_Report_ST3a.pdf (accessed on 15 July 2020).

16. ISO 9869:1994. In-Situ Measurement of Thermal Resistance and Thermal Transmittance; International Standarization Organization: Geneva, Switzerland, 1994.

17. Johnston, D.; Miles-Shenton, D.; Farmer, D.; Wingfield, J. Whole House Heat Loss Test Method (Coheating). 2013. Available online: http://www.leedsbeckett.ac.uk/as/cebe/projects/cebe_coheating_test_method_june2013. pdf (accessed on 15 July 2020).

18. Jack, R.; Loveday, D.; Allinson, D.; Lomas, K. First evidence for the reliability of building coheating tests. Build. Res. Inf. 2017, 46, 383-401. [CrossRef]

19. Gasparella, A.; Pernigotto, G.; Baratieri, M.; Baggio, P. Thermal dynamic transfer properties of the opaque envelope: Analytical and numerical tools for the assessment of the response to summer outdoor conditions. Energy Build. 2011, 43, 2509-2517. [CrossRef]

20. Ballarini, I.; Corrado, V. Analysis of the building energy balance to investigate the effect of thermal insulation in summer conditions. Energy Build. 2012, 52, 168-180. [CrossRef] 
21. Diao, R.D.; Sun, L.; Yang, F. Thermal performance of building wall materials in villages and towns in hot summer and cold winter zone in China. Appl. Therm. Eng. 2018, 128, 517-530. [CrossRef]

22. Suleiman, B.M. Estimation of U-value of traditional North African houses. Appl. Therm. Eng. 2011, 31, 1923-1928. [CrossRef]

23. Rodrigues, E.; Soares, N.; Fernandes, M.S.; Rodrigues Gaspar, A.; Gomes, A.; Costa, J.J. An integrated energy performance-driven generative design methodology to foster modular lightweight steel framed dwellings in hot climates. Energy Sustain. Dev. 2018, 44, 21-36. [CrossRef]

24. Ahmad, N.; Ghiaus, C.; Thiery, T. Influence of Initial and Boundary Conditions on the Accuracy of the QUB Method to Determine the Overall Heat Loss Coefficient of a Building. Energies 2020, 13, 284. [CrossRef]

25. Oliveti, G.; Arcuri, N.; Mazzeo, D.; De Simone, M. A new parameter for the dynamic analysis of building walls using the harmonic method. Int. J. Therm. Sci. 2015, 88, 96-109. [CrossRef]

26. Mazzeo, D.; Oliveti, G.; Arcuri, N. Influence of internal and external boundary conditions on the decrement factor and time lag heat flux of building walls in steady periodic regime. Appl. Energy 2016, 164, 509-531. [CrossRef]

27. Strachan, P.A.; Baker, P.H. Special issue on outdoor testing, analysis and modelling of building components. EDITORIAL. Build. Environ. 2008, 43, 127-128. [CrossRef]

28. Jiménez, M.J.; Porcar, B.; Heras, M.R. Application of different dynamic analysis approaches to estimate the U value of building components. Build. Environ. 2009, 44, 361-367. [CrossRef]

29. Díaz-Hernández, H.P.; Torres-Hernández, P.R.; Aguilar-Castro, K.M.; Macias-Melo, E.V.; Jiménez, M.J. Data-Based RC Dynamic Modelling Incorporating Physical Criteria to Obtain the HLC of In-Use Buildings: Application to a Case Study. Energies 2020, 13, 313. [CrossRef]

30. Gutschker, O. Lord-Modelling and Identification Software for Thermal Systems, User Manual; BTU Cottbus: Cottbus, Germany, 2004.

31. Chávez, K.; Ruiz, D.P.; Jiménez, M.J. Dynamic integrated method applied to assessing the in-situ thermal performance of walls and whole buildings. Robustness analysis supported by a benchmark set-up. Appl. Therm. Eng. 2019, 152, 287-307. [CrossRef]

32. Rouchier, S.; Jiménez, M.J.; Castaño, S. Sequential Monte Carlo for on-line parameter estimation of a lumped building energy model. Energy Build. 2019, 187, 86-94. [CrossRef]

33. Godfrey, R. Correlation Methods. Automatica 1980, 16, 527-534. [CrossRef]

34. Jiménez, M.J.; Madsen, H.; Bloem, H.; Dammann, B. Estimation of non-linear continuous time models for the heat exchange dynamics of building integrated photovoltaic modules. Energy Build. 2008, 40, 157-167. [CrossRef]

35. Castillo, L.; Enríquez, R.; Jiménez, M.J.; Heras, M.R. Dynamic integrated method based on regression and averages, applied to estimate the thermal parameters of a room in an occupied office building in Madrid. Energy Build. 2014, 81, 337-362. [CrossRef]

36. International Standarization Organization. ISO Guide to the Expression of Uncertainty in Measurement; International Standarization Organization: Geneva, Switzerland, 1995; ISBN 92-67-10188-9.

37. Gutschker, O. Parameter identification with the software package LORD. Build. Environ. 2008, 43, 163-169. [CrossRef]

38. Soutullo, S.; Sánchez, M.N.; Enríquez, R.; Jiménez, M.J.; Heras, M.R. Empirical estimation of the climatic representativeness in two different areas: Desert and Mediterranean climates. Energy Procedia 2017, 122, 829-834. [CrossRef]

(C) 2020 by the authors. Licensee MDPI, Basel, Switzerland. This article is an open access article distributed under the terms and conditions of the Creative Commons Attribution (CC BY) license (http://creativecommons.org/licenses/by/4.0/). 